\title{
Review Article \\ State of the Art Study on Aging of Asphalt Mixtures and Use of Antioxidant Additives
}

\author{
Okan Sirin $\mathbb{D D}^{1}$, Dalim K. Paul $\left(\mathbb{D},{ }^{2}\right.$ and Emad Kassem ${ }^{3}{ }^{3}$ \\ ${ }^{1}$ Department of Civil and Architectural Engineering, Qatar University, P.O. Box 2713, Doha, Qatar \\ ${ }^{2}$ Ashghal Research and Development Center, Public Works Authority, Doha, Qatar \\ ${ }^{3}$ Department of Civil and Environmental Engineering, University of Idaho, 875 Perimeter Drive MS 1022, Moscow, \\ ID 83844, USA \\ Correspondence should be addressed to Okan Sirin; okansirin@qu.edu.qa
}

Received 8 October 2017; Revised 14 January 2018; Accepted 21 January 2018; Published 29 March 2018

Academic Editor: Hossein Moayedi

Copyright (c) 2018 Okan Sirin et al. This is an open access article distributed under the Creative Commons Attribution License, which permits unrestricted use, distribution, and reproduction in any medium, provided the original work is properly cited.

\begin{abstract}
The detrimental effects of hardening in asphalt pavements were first recognized by pioneering pavement engineers in the 1900 s and have been studied extensively during the last 70 years. This hardening process, referred to as asphalt aging, is generally defined as change in the rheological properties of asphalt binders/mixtures due to changes in chemical composition during construction and its service life period. Aging causes the asphalt material to stiffen and embrittle, which affects the durability and leads to a high potential for cracking. This paper presents the state of the art on asphalt and asphalt mixture aging and use of antioxidant additives to retard the aging. A picture of complex molecular structure of asphalt and its changes due to atmospheric condition and various protocols used to simulate aging in laboratory environment are also discussed. Emphasis is given on recent studies on simulation of aging of asphalt mixtures as there has been limited research on mixtures compared to the asphalt binder. Finally, this paper presents the application of antiaging techniques and its mechanism, use of various types of antioxidant additives to retard aging of asphalt and, hence, improve the performance of asphalt pavements.
\end{abstract}

\section{Introduction}

Asphalt is the most widely used binding material in road pavements all over the world. Approximately $95 \%$ of asphalt that are produced worldwide each year is applied in the paving industry [1]. Asphalt essentially acts as a binder for mineral aggregates to form asphalt mixes, also called asphalt concrete or bituminous mixes. The first use of asphalt in road construction during the era of Nabopolassar, King of Babylon (625-604 BC), was mentioned by Abraham [2]. However, bitumen essentially disappeared from the pavements until the discovery of European sources of natural bitumen which led to the development of the modern applications for this material [1]. Asphalt paved roads have been in operation in Europe since the 1850s [3] and in the United States for about 125 years [4]. Pioneering pavement engineers $[2,5]$ observed a strong effect of temperature on its consistency and soon realized that hardening or aging of asphalt occurs during mixing, construction, and operation affecting the performance of asphalt pavement [6].

The term aging may be applied to describe multiple mechanisms in asphalt binder/mixture. Hence, it seems necessary to clarify the terminology used by pavement engineers. In pavement engineering, change in the rheological properties of asphalt binders/mixtures is due to changes in chemical composition during construction and its service life period.

Aging of asphalt binders occurs during the production of asphalt mixtures and while in service when exposed to the surrounding environment. The first stage of aging occurs at a very fast rate when asphalt mixture is produced at a very high temperature. This stage is often referred to as shortterm aging. During this stage, a very thin film of asphalt is exposed to air at elevated temperatures, leading to a significant change in the rheological properties of the asphalt binders. Such changes are presented in high viscosity and 


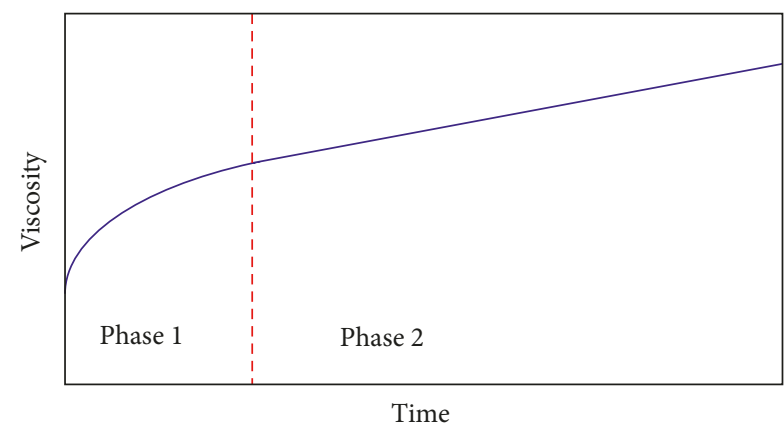

FIGURE 1: Typical hardening response for asphalt binder (after Glover et al. [8]).

increased stiffness [7]. The second stage of aging occurs when the asphalt is exposed to the environment as in-service pavement at a relatively lower temperature for a long duration. The rate of hardening depends on the in-place air void content and surrounding environment.

Figure 1 shows a typical hardening response for unmodified asphalt binder. There is a jump in the viscosity of the asphalt binder due to short-term aging (Phase 1), while there is a linear increase at a lower constant rate with time (Phase 2). Phase 2 represents hardening due to long-term aging.

There are several factors that influences asphalt aging. External factors include plant type, mixing temperature and silo storage time during short-term aging, and in-field conditions (i.e., temperature, ultraviolet (UV) ray, and rainfall) and time during long-term aging. The rate and extent of aging also depends on mixture properties such as source and type of asphalt, aggregate gradation and absorption, void content/permeability, and the thickness of asphalt binder film over the aggregate. Table 1 summarizes various factors and their effects on the short- and long-term aging of asphalt. A recent study by Morian et al. [9] reported that mixtures' effective binder content has provided the strongest indicator on the aging characteristics of asphalt mixture, irrespective of the type of granular aggregate.

Aging causes several changes in asphalt mix properties which are reflected in the performance of asphalt pavement. Results from experimental studies [33] demonstrated that ductility and penetration of asphalt binder are reduced while softening point and ignition temperature are increased as a result of aging. Ultimately, viscosity of the asphalt is increased and becomes a stiffer asphalt mixture. Increase in viscosity up to 10 times due to 5-year field aging in the Middle East conditions was observed as shown in Figure 2 [34].

Regarding mechanical properties, the stiffness modulus also increases due to aging (Figure 3), and this increase can be up to 4 times depending on the type of asphalt [35]. This may cause the mixture to become excessively hard and brittle and susceptible to disintegration and fatigue cracking at low temperatures [36-38]. Aging may also render the mixture less durable than the original mixture, in terms of wear resistance and moisture susceptibility [39]. As a result, damage tolerance of asphalt layer reduces, and many highway and airfield pavements in service fail prematurely. However, aging is not necessarily a negative phenomenon since the resistance of the asphalt mixture to permanent deformation and the load-bearing capacity is improved due to increased stiffness and cohesion. In some cases, aging may also help a mixture to achieve optimum properties [6].

This paper presents a comprehensive review of aging of asphalt paving materials with the following key focus areas:

(1) Comprehensive definition of asphalt aging and an overview of asphalt chemistry

(2) Critical discussion on aging mechanisms, corresponding changes in molecular structure, and its effect on the properties of asphalt materials

(3) Existing test methods, protocols, and techniques for assessing the aging of asphalt paving materials with an emphasis on recent studies on aging of asphalt mixtures

(4) Antiaging techniques and different types of additives and their mechanism to retard aging of asphalt to improve performance of asphalt pavement.

\section{Asphalt Chemistry and Aging Mechanisms}

Asphalt is either derived from natural deposits or obtained as a residue of crude petroleum or a product of solvent extraction of petroleum. It has a variable and complex elemental composition which depends primarily on its crude source. Asphalt is primarily composed of carbon (typically $80-88 \%)$ and hydrogen atoms (10-12\%) which gives a hydrocarbon content of around 90\% [41, 42]. The remaining portion consists of two types of atoms: heteroatoms and metals. Heteroatoms include nitrogen $(0-2 \%)$, oxygen $(0-$ $2 \%)$, and sulphur (0-9\%). Metal atoms are vanadium, nickel, and iron, and these atoms are present in trace quantities, typically far less than $1 \%[43,44]$. Table 2 shows elemental analysis of 8 different core asphalts of various crude origins.

The hydrocarbons constitute the basic structure of asphalt whereas the metal atoms provide indication or characteristic of asphalt crude source. Heteroatoms contribute to many of asphalt's unique chemical and physical properties by interacting with molecules. For example, sulphur reacts more easily than carbon and hydrogen to incorporate oxygen into the asphalt structure which leads to oxidative aging of asphalt [45].

According to Corbetts's method [46], these chemical elements combine to form the four main components or fractions of asphalt cement: asphaltenes, saturates, naphthalene aromatics, and polar aromatics (or resins), each of which provides different characteristics to asphalt. Asphaltenes and saturates are normally incompatible compounds and are brought together by aromatics. Asphaltenes are mainly responsible for viscosity (i.e., hardening effects) whereas abundance of aromatics and saturates decreases the ductility (i.e., elastic effects). Some researchers divide the asphalt into two broad chemical groups according to Rostler's methods of precipitation [47], namely asphaltenes and low molecular weight maltenes. 
TABLE 1: Factors affecting aging of asphalt mixture.

\begin{tabular}{|c|c|c|c|}
\hline & Factors & Findings & References \\
\hline \multirow{12}{*}{ Short-term aging } & Binder chemistry & Major effect & Traxler $[10]$ \\
\hline & Binder type and source & Significant effect on field aging & Lund and Wilson $[11,12]$ \\
\hline & Binder type and source & Significant effect on lab aging; & Topal and Sengoz [13] \\
\hline & Binder type and source & reduced aging with polymer & Zhao et al. [14], Morian et al. [15] \\
\hline & Asphalt binder film thickness & Significant effect & Kandhal and Chakraborty [16] \\
\hline & & No effect & Chipperfield and Welch [17] \\
\hline & Aggregate gradation & Important effect & Morian et al. [15] \\
\hline & & Major effect & Traxler $[10]$ \\
\hline & Aggregate absorption & Important effect & $\begin{array}{l}\text { Aschenbrener and Far [18], } \\
\text { Morian et al. [15] }\end{array}$ \\
\hline & $\begin{array}{c}\text { Inclusion of recycled materials } \\
\text { and reheating }\end{array}$ & Significant effect & Mogawer et al. [19] \\
\hline & Plant type & Significant effect & $\begin{array}{l}\text { Terrel and Holen [20], } \\
\text { Chollar et al. [21] }\end{array}$ \\
\hline & $\begin{array}{l}\text { Production temperature } \\
\text { and silo storage }\end{array}$ & Significant effect & $\begin{array}{l}\text { Mogawer et al. [19], } \\
\text { Daniel et al. [22] }\end{array}$ \\
\hline \multirow{16}{*}{ Long-term aging } & Aggregate source & No effect on lab aging & Morian et al. [15] \\
\hline & Aggregate porosity & Significant effect & Kemp and Predoehl [23] \\
\hline & Binder source & Significant effect & Morian et al. [15] \\
\hline & & Significant effect & Kari [24] \\
\hline & Asphalt content & No effect & Rolt $[25]$ \\
\hline & & & Kemp and Predoehl [23] \\
\hline & Air voids & Significant effect & Harrigan [26], Houston et al. [27] \\
\hline & & No effect & Rolt [25] \\
\hline & Pavement permeability & Significant effect & Kari [24] \\
\hline & \multirow{4}{*}{ Pavement depth } & Field aging not limited to the top & \\
\hline & & $\begin{array}{l}25 \mathrm{~mm} \text { of the pavement; field aging } \\
\text { gradient observed }\end{array}$ & Farrar et al. [28] \\
\hline & & Aging decreases over depth & Sirin et al. [29] \\
\hline & & $\begin{array}{l}10 \text {-year field aging can result in } \\
\text { deterioration to the } 2 \text { nd layer }\end{array}$ & Wu et al. [30] \\
\hline & In-service temperature & Significant effect & $\begin{array}{l}\text { Kemp and Predoehl [23], } \\
\text { Rolt [25], } \\
\text { Epps Martin et al. [31], } \\
\text { Sirin et al. }[28]\end{array}$ \\
\hline & Exposure time & Significant effect & Rolt [25] \\
\hline & Ultraviolet ray & Significant effect & Lee [32] \\
\hline
\end{tabular}

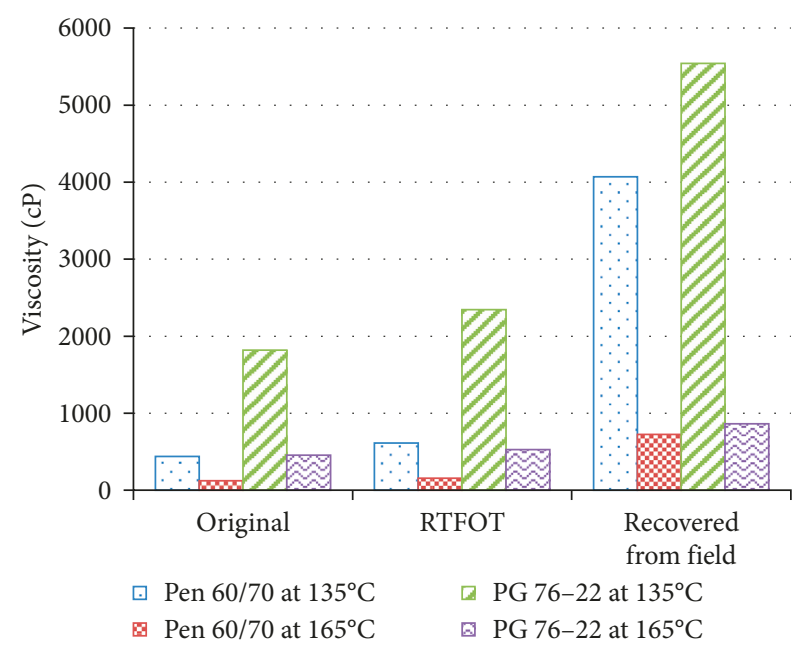

FigURE 2: Effect of 5-year aging on the viscosity of asphalt binders.

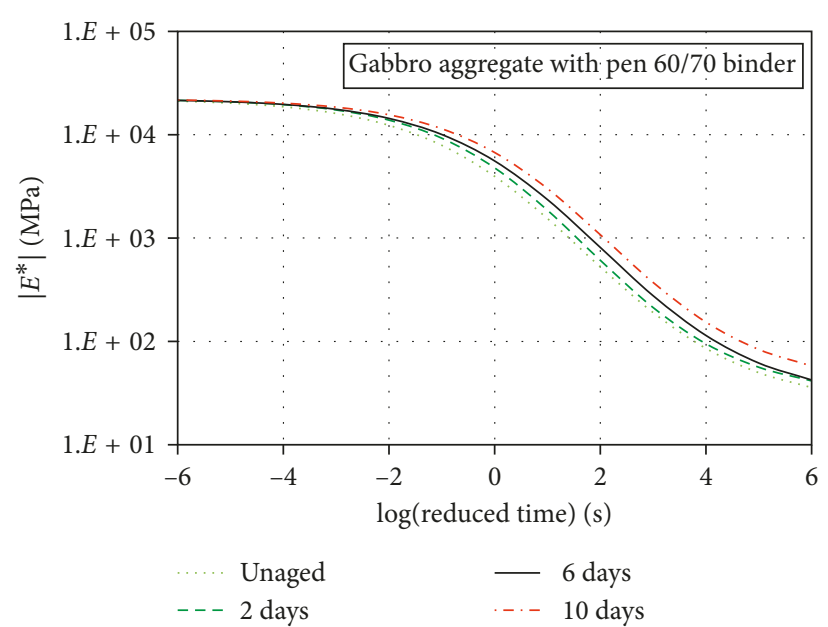

FIgURE 3: Effect of long-term aging duration on dynamic modulus [40]. 
TABLE 2: Elemental and component analysis of SHRP core asphalts by Asphalt Institute (from Mortazavi and Moulthrop [42]).

\begin{tabular}{|c|c|c|c|c|c|c|c|c|}
\hline $\begin{array}{l}\text { Asphalt code and crude } \\
\text { source }\end{array}$ & $\begin{array}{l}\text { AAA-1 } \\
\text { Canada }\end{array}$ & $\begin{array}{l}\text { AAB-1 } \\
\text { USA }\end{array}$ & $\begin{array}{l}\text { AAC-1 } \\
\text { Canada }\end{array}$ & $\begin{array}{l}\text { AAD-1 } \\
\text { USA }\end{array}$ & $\begin{array}{l}\text { AAF-1 } \\
\text { USA }\end{array}$ & $\begin{array}{l}\text { AAG-1 } \\
\text { USA }\end{array}$ & $\begin{array}{c}\text { AAK-1 } \\
\text { Venezuela }\end{array}$ & $\begin{array}{l}\text { AAM-1 } \\
\text { USA }\end{array}$ \\
\hline \multicolumn{9}{|l|}{ Elemental analysis } \\
\hline C (\%) & 83.9 & 82.3 & 86.5 & 81.6 & 84.5 & 85.6 & 83.7 & 86.8 \\
\hline $\mathrm{H}(\%)$ & 10.0 & 10.6 & 11.3 & 10.8 & 10.4 & 10.5 & 10.2 & 11.2 \\
\hline $\mathrm{H}+\mathrm{C}(\%)$ & 93.9 & 92.9 & 97.8 & 92.4 & 94.9 & 96.1 & 93.9 & 98.0 \\
\hline $\mathrm{O}(\%)$ & 0.6 & 0.8 & 0.9 & 0.9 & 1.1 & 1.1 & 1.0 & 0.5 \\
\hline N (\%) & 0.5 & 0.5 & 0.7 & 0.8 & 0.6 & 1.1 & 0.7 & 0.6 \\
\hline$S(\%)$ & 5.5 & 4.7 & 1.9 & 6.9 & 3.4 & 1.3 & 6.4 & 1.2 \\
\hline $\mathrm{V}(\mathrm{ppm})$ & 174 & 220 & 146 & 310 & 87 & 37 & 1480 & 58 \\
\hline $\mathrm{Ni}(\mathrm{ppm})$ & 86 & 56 & 63 & 145 & 35 & 95 & 142 & 36 \\
\hline $\mathrm{Fe}(\mathrm{ppm})$ & $<1$ & 16 & - & 13 & 100 & 48 & 24 & 255 \\
\hline \multicolumn{9}{|l|}{ Component analysis } \\
\hline Asphaltene (\%) & 18.3 & 18.2 & 11.0 & 23.0 & 14.1 & 5.8 & 21.1 & 3.9 \\
\hline Saturates $(\%)$ & 10.6 & 8.6 & 12.9 & 8.6 & 9.6 & 8.5 & 5.1 & 1.9 \\
\hline Polar aromatics $(\%)$ & 37.3 & 38.3 & 37.4 & 41.3 & 38.3 & 51.2 & 41.8 & 50.3 \\
\hline Nanthelene aromatics (\%) & 31.8 & 33.4 & 37.1 & 25.1 & 37.7 & 32.5 & 30.0 & 41.9 \\
\hline
\end{tabular}

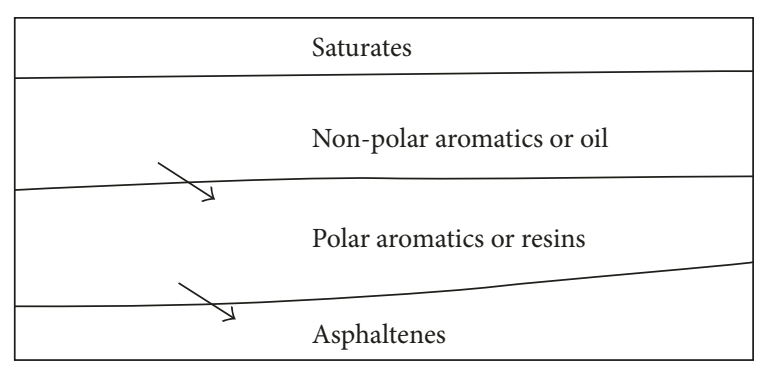

$\longrightarrow$ Time

FIGURE 4: Effect of aging on the chemical composition of the asphalt (from Heneash [55]).

Maltenes are viscous liquids composing of resins and oils [48]. A complex mixture system of asphalt is formed upon chemical and physical interaction between these fractions [49-52]. A component analysis of different types of asphalt is presented in Table 1.

Researchers [53,54] used high pressure-gel permeation chromatographic (HP-GPC) to separate asphalt into different fractions and studied independently the effect of aging process on asphalt components. Studies regarding chemical composition of asphalt through aging indicate that the asphaltenes content is increased, while the resins and aromatics contents decrease. As a result of increase in asphaltenes content, the asphalt become harder (i.e., stiffer), and that could be easily manifested as decreasing of penetration and increasing softening point and viscosity [55]. Figure 4 shows the effect of aging on the chemical composition of a typical asphalt binder. Researchers also indicated that due to aging, the asphaltenes/maltenes ratio changes causing an increase in bitumen viscosity, becoming more hard and brittle [1].

Physical and chemical properties of asphalts change over time due to the exposure to various environmental conditions in the field during their service life. Since the 1930s, research has continued to develop an understanding of the mechanisms contributing to short- and long-term aging [56]. Mechanisms causing binder aging include oxidation, volatilization, thixotropy (or steric hardening), polymerization due to actinic light, and condensation polymerization due to heat $[6,10,51,57]$. Among them, oxidation, volatilization, and steric hardening are considered the main mechanisms associated with the aging process of asphalt mixtures [51, 57-59]. During production, laying, and compaction, asphalt mixture is subjected to higher temperature which causes aging due to oxidation and loss of volatile compounds. On the contrary, long-term aging during service periods takes place at lower temperature primarily due to oxidation mechanism [60].

2.1. Oxidation. Many researchers have addressed binder oxidation chemistry $[8,52,61-63]$. Oxidation is the irreversible chemical reaction between oxygen molecules and the component species of bulk asphalt resulting in significant alterations to the desired physical and/or mechanical properties of asphalt. Oxidative aging of asphalt is believed to be caused by the generation of oxygen-containing polar chemical functionalities on asphalt molecules, which in turn can cause agglomeration among molecules due to increased chemophysical associations such as hydrogen bonding, van der Waals force, and Coulomb force [41, 64, 65].

The effect of binder oxidation in pavement on its performance is rather contradictory. Asphalt's complex organic components react with atmospheric oxygen and ultraviolet (UV) radiation, and as a consequence, the pavement surface is hardened which leads to cracks. Coons and Wright [66] reported that binder oxidation occurs only in the top inch of the pavement and that below the top inch; the binder is left virtually unaffected by years of use and years of environmental exposure. Recently developed Mechanistic Empirical Pavement Design Guide [67] also assumes in its calculation that binders oxidize only in the top inch. As a consequence, binder oxidation and the resulting increase in pavement stiffness actually can have a positive, beneficial impact on pavement fatigue life [8]. 
However, Walubita et al. [68] and Walubita [69] indicated that binder oxidation in pavements can have a very significant negative impact on pavement fatigue life. More profound evidence of pavement hardening well below the surface has been reported based on extensive data by Glover et al. [70] and Al-Azri et al. [71] where a large number of Texas pavements were cored, the binder extracted and recovered, and then tested to determine binder stiffness as a function of age of the pavement. Increase in stiffness and a decrease in the ductility of the asphalt mixtures is reported due to oxidation, which could reduce its resistance to fatigue cracking [72].

Asphalt oxidation produces changes in the chemical composition of asphalt. Saturates remain essentially unchanged due to their low chemical reactivity whereas other three fractions exhibit significant variations [73, 74]. As a result, functional groups (i.e., carbonyl and sulfoxide groups) are formed in asphalt molecules leading to decreased aromatic fractions and increased asphaltenes fractions [1]. Many attempts have been taken to quantify oxidation for better understanding of asphalt aging. Liu et al. [75] indicated that as the area of carbonyl region (CA) in FTIR spectra is a direct measure of binder oxidation and the percentage of carbonyl compounds can be used to assess the changes due to oxidative aging [8]. The content of carbonyl depends on the temperature and oxygen partial pressure.

The carbonyl reaction rate is described by [8]

$$
\frac{d \mathrm{CA}}{d t}=r_{\mathrm{CA}}=A P^{\propto} e^{-E / \mathrm{RT}}
$$

where $d \mathrm{CA} / d t=$ carbonyl reaction rate, $A=$ frequency factor, $P=$ pressure, $\propto$ = reaction order, $E=$ activation energy, $R=$ gas constant, and $T=$ absolute temperature. Studies show that the values of $A, E$, and $\propto$ differ for different asphalt types.

2.2. Volatilization. Volatilization is another important mechanism that occurs during hot mixing and construction of asphalt cement. At high temperatures, lighter molecular weight can vaporize and escape into the atmosphere $[1,10]$. This may be more significant in the preparation of modified asphalt binders where oil-like compounds are evaporated from the asphalt. When thin asphalt film comes into contact with aggregates at temperatures of $150^{\circ} \mathrm{C}$ or higher, aromatic fractions rapidly evaporate, and asphaltene fractions generally increase between 1 and 4\% [76]. Fumes and steams are generated as a result of this reaction depending on the contact surface area between the asphalt film and the aggregates [77]. As a result of weight loss, asphalt flow properties are reduced, that is, viscosity is affected by volatilization, especially given the speed with which volatilization takes place $[78,79]$. Researchers $[6,80]$ have found that viscosity increases from 150 to $400 \%$. Significant increase of modulus and decrease of phase angle were observed because of volatilization [81]. Anderson and Bonaquist [60] suggested that quantifying the amount of volatile compound loss is essential for better understanding of asphalt hardening during short-term aging.
2.3. Steric Hardening. Steric hardening, also known as physical hardening, occurs over time when asphalt cements are exposed to low temperature. In this process, molecular structure of asphalt is reorganized, affecting its asphaltene fractions [82]. Consequences of steric hardening are increased viscosity, slight volume contraction, and ultimately the hardening of asphalt $[10,83]$. Steric hardening is more pronounced at temperatures close to $0^{\circ} \mathrm{C}$ and must be considered while testing asphalt at very low temperature. As this hardening is a result of structural reorganization of the molecule at low temperatures [51], it can be reversed through heat or mechanical work [84].

\section{Laboratory Accelerated Aging and Evaluation Methods}

Asphalt is aged in laboratory environment at a faster rate through heat and air application to simulate field aging and hence to predict performance of asphalt pavement. Earliest work to simulate aging in laboratory was by Dow [5] who used extended heating test. Since then, many research efforts $[6,10,27,50,57,85-99]$ have been devoted to assess effect of aging on the performance of asphalt materials. After aging acceleration treatment, samples are usually studied to quantify changes in the asphalt binder/mixture properties before and after the aging treatment (commonly known as aging index). Properties examined during aging studies are generally weight loss, viscosity, penetration, ductility, tensile strength, and stiffness modulus.

Treatment of asphalt or tests related to aging of asphalt materials can be broadly divided into two categories, namely, tests performed on asphalt binder and tests performed on asphalt mixtures. Therefore, discussion of the work is represented in the following two sections: binder studies and mixture studies.

3.1. Binder Studies. Researchers have devised several testing methods to characterize properties of asphalt binders by simulating aging of asphalt in a hot mix plant and during service period life of pavement. Most of these researches have used thin film ovens to age asphalt by applying extended heating and air blowing (or oxidation) procedure. The most commonly used and standard tests for simulation of asphalt hot-mix aging are the Rolling Thin-Film Oven Test ((RTFOT) ASTM D2872 [100], AASHTO T240 [101]) and Thin-Film Oven Test ((TFOT) ASTM D1754 [102], AASHTO T179 [103]). Pressure aging vessel (PAV) is used to simulate long-term aging of asphalt binder that is experienced in the field [104]. In the current Superpave binder specifications, an asphalt binder to be evaluated is to be subjected RTFOT for short-term aging at $163^{\circ} \mathrm{C}$ for 85 minutes followed by a PAV process in order to simulate several years of field aging.

The TFOT was first introduced by Lewis and Welborn [105] to simulate short-term aging by applying a temperature of $163^{\circ} \mathrm{C}$ on asphalt of film thickness of $3.2 \mathrm{~mm}$ for 5 hours. However, researchers criticized TFOT due to a film thickness much thicker than that is commonly observed in 


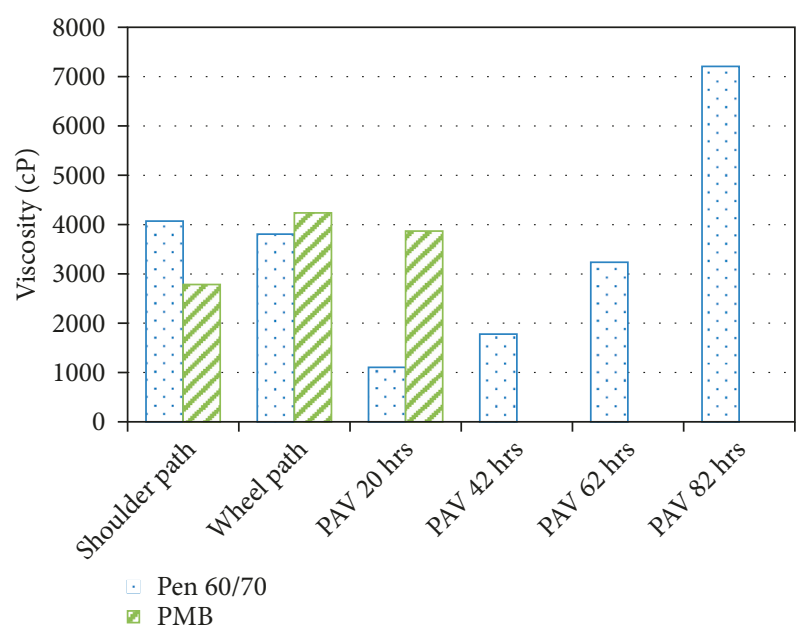

Figure 5: Comparison of PAV-aged binders with binders recovered from 5-year old pavement (after Sirin et al. [34]).

the field and nonuniform aging throughout the depth of asphalt [58]. Many researchers attempted to develop or improve testing methods to age asphalt with more representative film thickness. One such effort was the Modified thin film oven test by Edler et al. [106] who utilized a film thickness of $100 \mu \mathrm{m}$ with an additional increased exposure time of 24 hours. Researchers also proposed some other testing methods such as Shell microfilm test [107], Rolling microfilm oven test [108], Tilt-oven durability test [23], and Thin film accelerated aging test [92] for better simulation of asphalt binder aging.

The most significant modification of the TFOT was the RTFOT, developed by the California Division of Highway [109], where eight glass bottles each containing $35 \mathrm{gm}$ of asphalt are aged by applying heat and oxidation on thin films of $1.25 \mathrm{~mm}$. This method ensures uniform aging of asphalt with no skin formation and correlates asphalt hardening reasonably well with that observed in hot-mixing process [110]. However, several researchers [111-113] identified a number of deficiencies (e.g., spilling out from RTFOT bottles) in RTFOT especially while testing modified asphalt binders. To overcome these limitations, researchers developed improved testing methods such as Modified Rolling Thin Film Oven Test ((RTFOTM) Bahia et al. [96]), Modified German Rotating Flask $[111,114]$ (MGRF), and Stirred Air Flow Test [115] (SAFT) to evaluate short-term aging of neat and modified asphalt binder.

Although thin film oven tests can adequately simulate short-term aging of asphalt binder, they lack of accuracy in predicting long-term aging during service period life of pavement. To predict long-term aging, a number of attempts have been made by combining thin film oven tests with oxidative aging such as Iowa durability test [32], Pressure oxidation bomb [106], Accelerated aging test device [116], PAV [80, 117], and High pressure aging test [118]. Among them, PAV treatment is believed to be the most reliable method to simulate long-term aging. In this process, RTFOT aged asphalt is subjected to $100^{\circ} \mathrm{C}$ for 20 hours at $2.07 \mathrm{MPa}$ pressure to reproduce field aging effects. It generally simulates aging of $8-10$ years of pavement service life according to USA standards [79]. However, 20 hours conditioning in PAV may not be sufficient for severe weather conditions like in the Middle East where up to 70 hours of conditioning may be needed to simulate the field aging of a 5year old asphalt pavement (Figure 5).

In a recent NCHRP study (Project number 9-36), Anderson and Bonaquist [60] attempted to develop an improved procedure to replace both RTFOT and PAV by a single apparatus for simulating short- and long-term aging. They examined both MGRF and SAFT, but with different operating conditions. Attempts with MGRF were not successful however SAFT with a modified impeller was proved to be successful to some extent to simulate both the shortterm and long-term aging of asphalt binder.

Atomic force microscopy (AFM) is often used to study the aging of asphalt binder in microscopic level and evaluate the change in micromechanical and microrheological properties. AFM is a nondestructive imaging tool that can deliver the surface topography, stiffness, tackiness information, and molecular interaction at microlevel of materials $[119,120]$. In AFM images, a bee-shaped (black and yellow stripes) structure is noticed, which indicates the asphaltene phase in bitumen $[121,122]$. The presence of such microstructures somewhat dictates the macroscale properties of bitumen, such as stiffness, viscoelasticity, plasticity, adhesion, fracture, and healing characteristics. Evolution of these microstructures with ageing and related to the resulting mechanical response is in focus to better understand the long-term properties of asphalts.

In recent days, AFM has become a popular technique and utilized by many researchers [123-126] to characterize the effect of short-term, long-term ageing, and ultraviolet (UV) radiation on the morphology of asphalt binders. An increase of bee-shaped microstructure with PAV aging was reported by Huang and Pauli [127], Wu et al. [128], and Zhang et al. [123]. Zhang et al. [123] showed that labsimulated aging affects the bitumen morphology significantly, and these changes in morphology are strongly correlated with the physical properties as well as chemical compositions of the binders before and after aging. The overall surface stiffness increased, and the bitumen surface became more solid-like [123]. Both asphaltenes content and the size of microstructures play a role in determining asphalt micromechanical properties [129]. Important relationships between microstructural changes depicted in AFM images and changes in composite viscoelastic properties obtained from the measurements were reported by Allen et al. [124]. Das et al. [126] found reduction in binder tackiness with aging, and as a result, adhesion of the asphalt binder specimens was negatively impacted causing an adhesive bond failure between binder and aggregates. The researchers reported the modulus of microstructure always being higher than the modulus of the matrix at the measured temperature, as shown in Figure 6. It was also noted that increase in modulus due to UV radiation exposure is higher than oxidation, and the highest value was always obtained after the combined exposure of UV and oxidation. Similar observation was found for 3 different binders of different sources. 


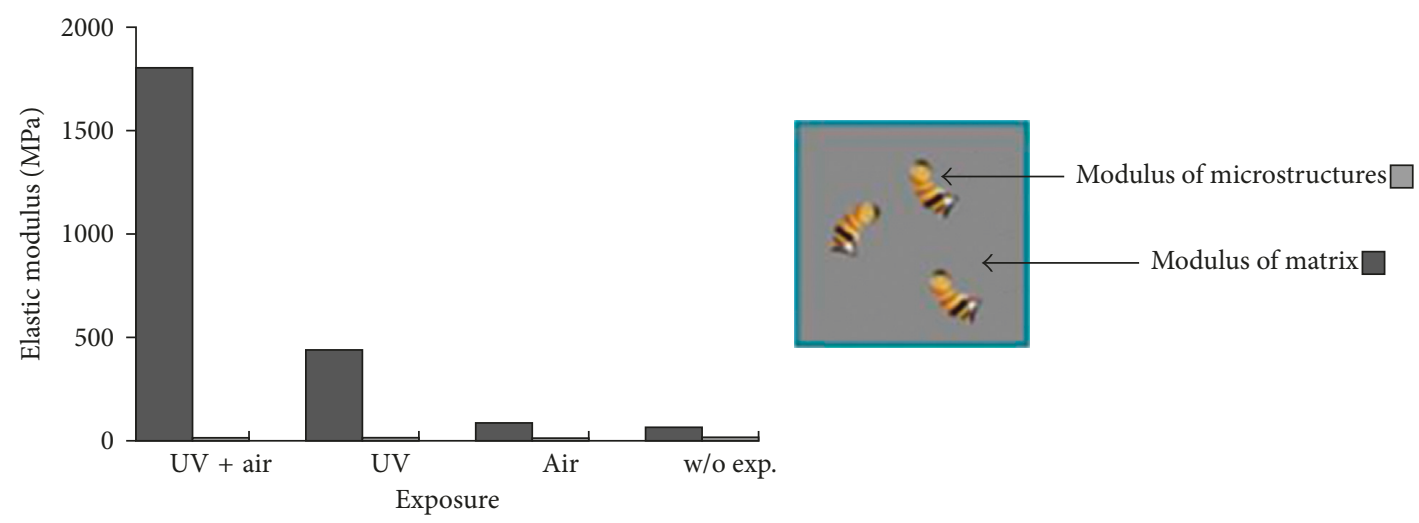

(a)

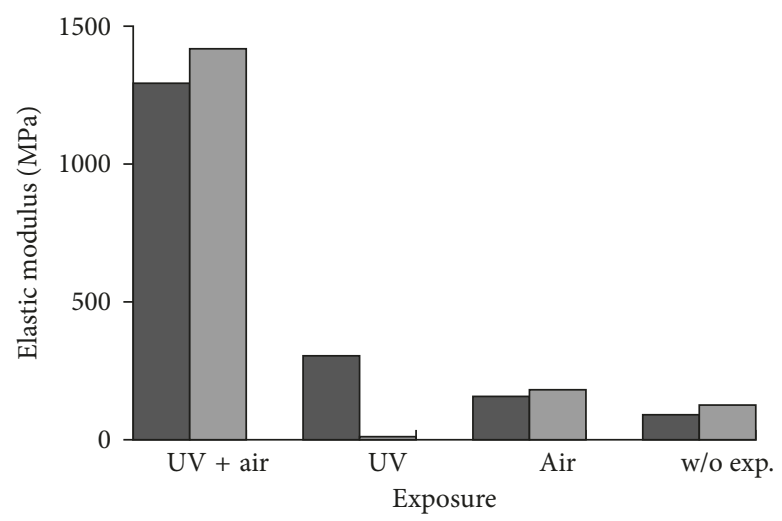

(b)

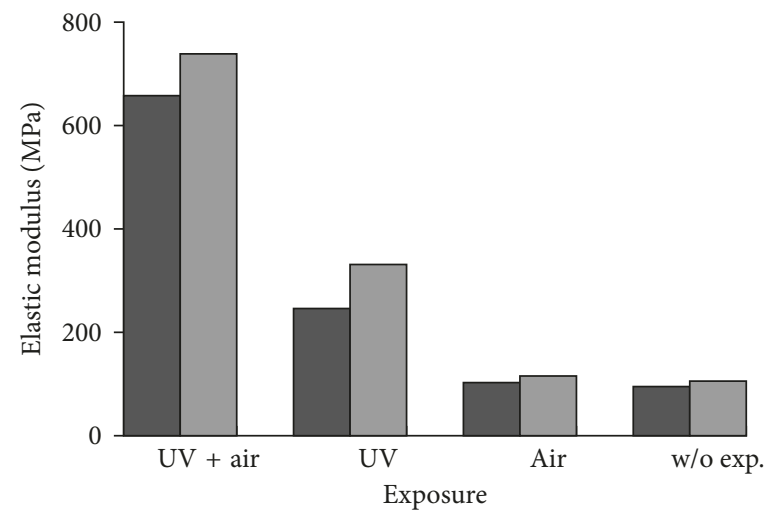

(c)

FiguRE 6: Variation in modulus measured using AFM at different levels of exposure for 3 different binders of different sources: (a) Bit-A, (b) Bit-B, and (c) Bit-C (from Das et al. [126]).

AFM had also been used to investigate the effect of aging on modified asphalt binders compared with the control binders $[127,128,130]$.

3.2. Mixture Studies. Compared to research on asphalt binder, there has been relatively little research on the aging of asphalt mixtures. Much of the early work on asphalt aging was conducted solely on the binders, without involving mixtures [6, 131]. Eventually, efforts have been seen to analyze aging of the asphalt-aggregate mixture system by measuring changes in penetration and viscosity of the extracted and recovered binders [91, 132-134]. Studies reported in NCHRP Project 9-6 [134] involved measurements and comparison of viscosity and penetration of the binders extracted and recovered from mixtures aged in the laboratory under various conditions with those from fieldproduced mixtures. Limited resilient modulus testing was also conducted on the laboratory-compacted samples. However, long-term aging properties, simulating 5 to 10 years in service, had to be extrapolated from the 2-year data available. More realistic approach to simulate asphalt mixture aging is to subject the asphalt mixtures to various 
TABLE 3: Temperature and time duration for different conditioning types.

\begin{tabular}{lcc}
\hline Conditioning type & Temperature & Time \\
\hline Conditioning for mixture design & Varies* & $2 \mathrm{hr}$ \\
Short-term aging & $135^{\circ} \mathrm{C}$ & $4 \mathrm{hr}$ \\
Long-term aging & $85^{\circ} \mathrm{C}$ & 5 days \\
\hline
\end{tabular}

*Mixture's specified compaction temperature and type of mixture (plantproduced, reheated, etc.).

aging conditions, measure the physical properties of the aged mixtures, and then compare with field aged specimens [57, 135, 136].

In recent studies on asphalt mixtures, the researchers indicated that nonuniform field aging of asphalt mixtures over depth and the surface of the asphalt pavement is found to be aged faster than the bottom [34, 137]. Embrittlement of asphalt mixture due to aging was reported by Rahmani et al. [38] and Elwardany et al. [138]. Brittleness increases with conditioning period under all aging modes, and over time in in-field service conditions [139]. As a result, fatigue cracking resistance and durability of asphalt mixtures is affected, which would be more notable as the temperature increases [140]. Gao et al. [141] showed that degradation in asphalt mixture elastic modulus increases with the increase in aging period. Azri and Mohseni [142] showed that different asphalt mixtures age in very different ways, and this will significantly affect their short-term and long-term rutting performances. Aging increased the permanent deformation resistance in terms of flow number, as reported by Islam et al. [139] and Babadopulos et al. [143].

3.2.1. Asphalt Mixture Aging Simulation Protocol. The current practice recommended by the American Association of State Highway and Transportation Officials (AASHTO) is to cure asphalt mixtures for a few hours and days for shortterm and long-term aging, respectively. The test procedure, based on the work done by Von Quintus et al. [90], covers three types of conditioning and presented in the AASHTO R30 standard procedure [144]:

(i) Mixture conditioning for volumetric mixture design

(ii) Short-term conditioning to simulate the aging that occurs during mixture mixing and placement

(iii) Long-term conditioning to simulate aging that occurs after the construction process and over the life of pavement

In this standard practice, the mixture is conditioned in a forced-draft oven for different periods of time and at different temperatures, as shown in Table 3.

3.2.2. Short-Term Aging Protocol. Research works have been conducted to evaluate the short-term aging protocol to simulate the aging of asphalt mixture during the production, laying, and construction of asphalt pavement layer. Although the performance test results of lab and plantproduced mixture were not an exact match, there was a general acceptance in the past that the laboratory aging was representative of field aging [145]. However, due to recent development in asphalt technology and changes in mixture components, mixture processing, and plant design, validity of current mix design methods in order to meet performance expectations is questioned.

In a comprehensive study, Bell et al. [57] evaluated the aging of asphalt mixture and found that the AASHTO shortterm aging protocol simulates asphalt mixture aging adequately well except few conservative predictions. Research conducted by the University of California at Berkeley in conjunction with Oregon State University and Austin Research Engineers, Inc. [57] also found the protocol to be adequate based on resilient modulus and indirect tensile test results. Aschenbrener and Far [18] conducted extensive investigation throughout Colorado, conditioned the mixtures at field compaction temperature for different durations (0-8 hours), and found the short-term aging protocol equivalent to 2-4 hours based on theoretical maximum density and asphalt absorption and 1-3 hours based on Hamburg wheel tracking test results. The researchers recommended conditioning the laboratory-produced mixtures for 2 hours at the field compaction temperature in order to simulate asphalt aging and absorption during plant production. Epps Martin et al. [31] also evaluated different short-term aging protocols, and the final recommendation was to condition lab mixture at $135^{\circ} \mathrm{C}$ for 2 hours before compaction.

3.2.3. Long-Term Aging Protocol. Researchers have used different conditioning procedures (extended heating, oxidation, and UV/Infrared treatment) to investigate the longterm aging of asphalt pavement. Conditioning may also be done either on loose mixture or on the compacted specimen. Oven aging on compacted specimen is commonly used to simulate the long-term aging of asphalt mixtures. However, in the compacted specimen, existence of oxidation gradient in radial direction and along the height of specimen was reported [27]. Hence, researchers [90, 138, 146-149] sometimes preferred conditioning loose mixture at elevated temperature due to homogeneity and efficiency of aging. However, compacting loose mix conditioned sample often was found to be problematic as mixture become too stiff due to loss of volatility of binder [148]. A significantly high number of gyration thus higher shear stress was required to compact loose mixtures specimen resulting in degradation in the aggregate structures hence changes the mixture properties [148, 150]. The temperature at which aging is executed is also important. Higher temperature $\left(>95^{\circ} \mathrm{C}\right)$ might cause slump/distortion and affects air distribution in the compacted specimen [148]. Loose mixture aging temperature more than $135^{\circ} \mathrm{C}$ results in a significant change in the relationship between asphalt binder rheology and chemistry and affects the mixture performance [151]. The optimal loose mixture aging temperature of $95^{\circ} \mathrm{C}$ is suggested by the researchers [138].

A number of studies [90, 138, 146, 147, 149, 152] showed that the long-term aging protocol can vary depending 
TABLE 4: Studies on the simulation of long-term aging of asphalt mixture.

\begin{tabular}{|c|c|c|}
\hline References & Aging & Findings \\
\hline Bell et al. [57] & $\begin{array}{l}0,2,4 \text {, and } 8 \text { days at } 85^{\circ} \mathrm{C} \\
1,2 \text {, and } 4 \text { days at } 100^{\circ} \mathrm{C}\end{array}$ & $\begin{array}{l}2 \text { days at } 85^{\circ} \mathrm{C} \text { or } 1 \text { day at } 100^{\circ} \mathrm{C}=1-3 \\
\text { years field aging } 8 \text { days at } 85^{\circ} \mathrm{C} \text { or } 4 \text { days } \\
\text { at } 100^{\circ} \mathrm{C}=9 \text { years of field aging }\end{array}$ \\
\hline Brown and Scholz [154] & 4 and 5 days at $85^{\circ} \mathrm{C}$ & $\begin{array}{l}5 \text { days at } 85^{\circ} \mathrm{C} \text { simulates long-term } \\
\text { aging of UK pavements; } 4 \text { days at } 85^{\circ} \mathrm{C} \\
\text { simulates } 15 \text { years old pavement in the } \\
\text { US }\end{array}$ \\
\hline $\begin{array}{l}\text { Harrigan [26] and } \\
\text { Houston et al. [27] }\end{array}$ & 5 days at 80,85 , and $90^{\circ} \mathrm{C}$ & $\begin{aligned} 5 \text { days at } 85^{\circ} \mathrm{C} & =7-10 \text { years of field } \\
& \text { aging }\end{aligned}$ \\
\hline Epps Martin et al. [31] & 1 to 16 weeks at $60^{\circ} \mathrm{C}$ & $\begin{array}{c}4-8 \text { weeks at } 60^{\circ} \mathrm{C}=\text { first summer of } \\
\text { field aging }\end{array}$ \\
\hline Islam et al. [139] & $\begin{array}{l}1,5,10,15,20 \text {, and } 25 \text { days } \\
\text { of oven aging at } 85^{\circ} \mathrm{C}\end{array}$ & $\begin{array}{c}\text { 1-day laboratory aging is close to } 1 \text {-year } \\
\text { of field aging }\end{array}$ \\
\hline Yin et al. [155] & $\begin{array}{l}2 \text { weeks at } 60^{\circ} \mathrm{C}, 3 \text { days at } \\
85^{\circ} \mathrm{C} \text { and } 5 \text { days at } 85^{\circ} \mathrm{C}\end{array}$ & $\begin{array}{c}2 \text { weeks at } 60^{\circ} \mathrm{C}=7-12 \text { months field } \\
\text { aging } 5 \text { days at } 60^{\circ} \mathrm{C}=12-23 \text { months } \\
\text { field aging }\end{array}$ \\
\hline \multirow{2}{*}{ Sirin et al. [29] } & $\begin{array}{c}0,3,7,15,30,45,60,90 \\
\text { and } 120 \text { days at } 85^{\circ} \mathrm{C} \text { on } \\
\text { compacted specimen }\end{array}$ & $\begin{array}{l}45 \text { and } 75 \text { days at } 85^{\circ} \mathrm{C}=5 \text { years field } \\
\text { aging in Middle East condition for } \\
\text { wearing and base course, respectively }\end{array}$ \\
\hline & $\begin{array}{c}0,1,2 \text {, and } 3 \text { days at } 135^{\circ} \mathrm{C} \\
\text { on loose mixtures }\end{array}$ & $\begin{array}{l}\text { 2-3 and 1-2 days at } 135^{\circ} \mathrm{C}=5 \text { years field } \\
\text { aging in Middle East condition for } \\
\text { wearing and base course, respectively }\end{array}$ \\
\hline
\end{tabular}

on the climatic conditions, laboratory aging method, laboratory aging temperature, or asphalt type. Furthermore, most of these studies only estimate the long-term aging of asphalt mixture without proper validation with field results, especially in the component level. The standard protocol to simulate the field aging is conditioning the compacted specimen at $85^{\circ} \mathrm{C}$ for 5 days in accordance with AASHTO R30.

The protocol uses a single temperature and does not account for different environmental conditions or mix properties. Thus, the applicability of the protocol to different climatic conditions (e.g., like in the Middle East) is questionable without field validation. Asphalt pavement experiences severe weather conditions at high temperatures (often exceeds $40^{\circ} \mathrm{C}$ during the summer months) in the Arabian Gulf region. Additionally, there is no precipitation during the summer and very little during the remainder of the year. These elevated temperatures increase binder oxidation significantly, which could lead to fatigue cracking and eventually pavement failure with heavy and repeated traffic loading. Previous studies also illustrate a need to develop an aging protocol that considers climate conditions, traffic volume, and mix properties $[27,57,136,153]$. These studies recommended considering these changes while in the design stage to better improve performance analysis of asphalt pavements.

Table 4 presents the key researches focused on the longterm aging simulation protocol. Bell et al. [57] included different climate zones to evaluate the long-term aging protocol of asphalt mixtures. Experimental results suggested conditioning the compacted specimen for 2 days at $85^{\circ} \mathrm{C}$ or 1 day at $100^{\circ} \mathrm{C}$ to simulate long-term aging of new pavements (1 to 3 years old). Mixture needed to condition for longer time ( 4 to 8 days for $85^{\circ} \mathrm{C}$ or 2 to 4 days for $100^{\circ} \mathrm{C}$ ) to predict aging of 9-10 years of field aging. However, the authors suggested avoiding the higher temperature of $100^{\circ} \mathrm{C}$ since conditioning the mixtures at this temperature could cause damage to the specimens. More importantly, the researchers recommended further research to achieve better validation and simulation for a wider range of climate zones. The researchers also recommended developing a model to simulate field aging using inputs that describe climate zones and traffic. Possible inputs could include traffic volume, maximum and minimum air temperature, average rainfall, age of pavements, and age of laboratory mixtures.

Romero and Roque [156] indicated that the use of the long-term aging procedures involving compacted mixes may not be better than the currently used short-term oven aging procedures and therefore long-term oven aging using the compacted asphalt samples should be discontinued. Houston et al. [27] performed a long-term aging study for different sites across the United States and for different aggregates and binders. The researchers considered conditioning the specimen at multiple temperatures $\left(80^{\circ} \mathrm{C}, 85^{\circ} \mathrm{C}\right.$, and $90^{\circ} \mathrm{C}$ ) for 5 days. High variability in the data from the selected sites were reported, and due to this variability and inability to account for various variables such as environmental conditions and mix properties, the researchers were not able to develop a new procedure or revise the current one for long-term conditioning of asphalt mixtures. It was concluded that the current standard procedure is not sufficient to truly simulate and predict the long-term aging of asphalt mixtures in the field. Developing a new procedure that accounts for different environmental conditions and mix properties such as air void content is highly desirable. In addition, they recommended including different types of materials: unmodified binders, modified binders, rubber binders, and reclaimed asphalt pavement. In a recent study, 
Yin et al. [156] proposed long-term aging protocols of 2 weeks at $60^{\circ} \mathrm{C}$ and 5 days at $85^{\circ} \mathrm{C}$ produced mixtures with equivalent in-service field ageing of 7-12 months and 12-23 months, respectively, considering WMA technology, recycled materials, aggregate absorption, polymer modified binder, and production temperature. Sirin et al. [29] indicated a severe aging of asphalt pavements in Middle East region due to harsh environmental condition. For such condition, it would require 45 and 75 days at $85^{\circ} \mathrm{C}$ on the compacted specimen to simulate 5 years field aging for wearing and base course, respectively. To avoid such a long conditioning period, the researchers suggested conditioning of the loose mixture as an alternative and found that it would take 2-3 and 1-2 days at $135^{\circ} \mathrm{C}$ to simulate the same level of aging for wearing and base course, respectively.

\section{Antioxidant Additives}

The control of asphalt aging is important because aging causes stiffening and brittleness that can lead to cracking and premature failure of asphalt pavement. As discussed in previous sections, there are several asphalt hardening mechanisms. Oxidation during asphalt mixture production, compaction, and in service is a major one and believed to be the most understood and the easiest to simulate in the laboratory [157, 158]. Therefore, researchers attempted to reduce/minimize oxidative hardening using chemical additives in order to obtain a longer lasting pavement and substantial savings in life cycle cost.

Additives that are used to modify asphalt and retard age hardening are called antioxidants. When antioxidants are added to asphalt as modifiers, they control oxidation by trapping or scavenging free radicals which are responsible for initiating and/or propagating oxidation. These antioxidants (e.g., lead diamyldithiocarbamate (LDADC)) act as sacrificial species that get oxidized instead of the asphalt binders [158, 159]. Some other antioxidants function by reacting with polar compounds and/or oxidation catalysts such as metals present in asphalts.

There are many antioxidants available for asphalt bitumen in the market. Based on the mode of controlling oxidation, antioxidants may be classified into four main groups: primary antioxidants, secondary antioxidants, metal chelators, and light stabilizers [158, 160]. The primary antioxidants have reactive $\mathrm{OH}$ or $\mathrm{NH}$ groups and function as free radical scavengers by either donating or accepting electrons from free radicals and thereby breaking the oxidation chain reactions. The secondary antioxidants include sulfur and phosphorous compounds such as sulphides, thioesters, disulphides, and phosphates. They function as peroxide or hydroperoxide decomposers by reducing them to stable compounds. Metal chelators operate by trapping trace metals such as vanadium, nickel, and iron which are believed to accelerate the formation of free radicals by acting as catalysts to the propagation step [160]. Finally, light stabilizers are used to prevent degradation by absorbing harmful radiant energy.
4.1. Studies on Antioxidant Additives to Retard Aging of Asphalt Mixture. Several studies reported the benefits of using antioxidant-modified binders. Although most of these studies are fairly old, some antioxidants (i.e., hydrated lime, lead antioxidants, and carbon black) hold promising results [50, 88, 160-164]. In these studies, the researchers used different additives to retard the oxidative hardening of asphalt binders and evaluated antioxidant systems by determining the degradation of asphalt physical properties, mainly the viscosity and ductility. However, most of these systems for retarding oxidative hardening have not performed satisfactorily in the field due to problems such as degradation, volatility, and loss of the antioxidant from the asphalt system.

A few recent studies were conducted to examine the effect of using antioxidant additives on binder performance (Table 5). Mohamed [165] evaluated the potential of CRABit (CR30 and CR50) as antioxidant modifier for use in dense asphalt mixtures (ACW14). The researcher conducted the study in two phases; first phase was to test the rheological characteristics of the new product by using wet mix through dynamic shear Rheometer (DSR) and the second phase included preparation of ACW14 mixture containing base and modified bitumen by dry mix and testing them to determine fundamental properties (i.e., resilient modulus, indirect tensile, creep, and fatigue resistance) before and after aging the specimen. The researcher found an improvement in the engineering properties and the performance with the modification, particularly with CR30.

Apeagyei et al. [166] evaluated the cracking potential of asphalt mixtures containing various levels of antioxidants. The researchers considered two levels of aging in a forceddraft oven to simulate short-term and long-term oven aging (STOA and SLOA, resp.) conditions. In addition, two levels of antioxidant modification were used: furfural (an aromatic aldehyde) and Dilauryl thiodipropionate (DLTDP-an antioxidant and thermal stabilizer) with the asphalt binders. Mixing percentages varied from $0.2 \%$ to $10 \% \mathrm{w} / \mathrm{w}$ of the base asphalt were incorporated into the base asphalt using a Barnant blender with a 2-inch blade operating at a speed of $750 \mathrm{rpm}$. The results showed that antioxidant-modified asphalt mixtures performed better than those with unmodified asphalt mixtures. The antioxidant-modified binders showed at least about 50\% lower flexural stiffness relative to an unmodified asphalt binder at a low temperature (about $-4^{\circ} \mathrm{C}$ to about $-58^{\circ} \mathrm{C}$ ), which indicated improved fatigue resistance. The modification also found to yield at least about $18 \%$ higher stiffness relative to an unmodified asphalt binder at a high temperature (from about $46^{\circ} \mathrm{C}$ to about $82^{\circ} \mathrm{C}$ ) indicating better rut resistance. In a separate study, Apeagyei [167] evaluated AOXADOUR as an antioxidative additive with PG 64-22 base binder and found higher dynamic modulus, improved rut resistance in terms of creep compliance, higher tensile strength at low temperature $\left(-10^{\circ} \mathrm{C}\right)$, and less effect of aging on fracture behavior for both STOA and LTOA conditioned specimen. AOXADUR-modified asphalt mixture showed less reduction in predicted life with aging and took longer time to critical cracking compared to control (Figure 7). 
Table 5: Studies on antioxidant additives.

\begin{tabular}{|c|c|c|c|}
\hline References & Antioxidant & Properties evaluated & Findings \\
\hline Mohammed [165] & CRABit (CR30 and CR50) & $\begin{array}{l}\text { Resilient modulus, indirect } \\
\text { tensile strength, creep, and } \\
\text { fatigue resistance }\end{array}$ & $\begin{array}{l}\text { Improvement in the engineering } \\
\text { properties and the performance } \\
\text { with the modification, } \\
\text { particularly with CR30 }\end{array}$ \\
\hline Apeagyei et al. [166, 167] & $\begin{array}{l}\text { Furfural and DLTDP; } \\
\text { AOXADUR }\end{array}$ & $\begin{array}{l}\text { Cracking potential, dynamic } \\
\text { modulus, creep compliance, and } \\
\text { tensile strength }\end{array}$ & $\begin{array}{l}\text { Antioxidant-modified asphalt } \\
\text { mixtures performed better than } \\
\text { those with unmodified asphalt } \\
\text { mixtures }\end{array}$ \\
\hline Apeagyei [59] & $\begin{array}{l}\text { DLTDP/furfural, hydrated lime, } \\
\text { vitamin E, carbon black, Irgafos } \\
\text { P-EPQ, and Irganox } 1010\end{array}$ & $\begin{array}{l}\text { Stiffness modulus, cracking } \\
\text { potential }\end{array}$ & $\begin{array}{l}\text { Furfural and DLTDP additives } \\
\text { provided a } 40 \text { percent reduction } \\
\text { in aging compared to unmodified } \\
\text { binders. Antioxidant-modified } \\
\text { binders had a lower stiffness } \\
\text { modulus and flexural stiffness } \\
\text { compared to untreated binders }\end{array}$ \\
\hline Reyes [168] & $\begin{array}{l}\text { Vitamin E as an antioxidant } \\
\text { modifier; hydrated lime and fly- } \\
\text { ash as stabilization agents }\end{array}$ & $\begin{array}{l}\text { Viscosity, stiffness, fatigue } \\
\text { resistance, rutting potential }\end{array}$ & $\begin{array}{l}\text { Vitamin E-modified binder } \\
\text { showed better resistance against } \\
\text { fatigue cracking but there is } \\
\text { concern on rutting resistance }\end{array}$ \\
\hline Pan et al. [52] & Coniferyl-alcohol lignin & Viscosity and ductility & $\begin{array}{l}\text { Coniferyl-alcohol lignin can } \\
\text { slower oxidation and hardening }\end{array}$ \\
\hline Williams [169] & $\begin{array}{l}\text { Agriculturally derived lignin- } \\
\text { containing ethanol coproducts } \\
\text { 3-12\% }\end{array}$ & $\begin{array}{c}\text { Rheological properties from DSR } \\
\text { and BBR }\end{array}$ & $\begin{array}{l}\text { Lignin-containing coproducts } \\
\text { showed beneficial antioxidant } \\
\text { activity and stiffened the binder } \\
\text { at all stages of aging }\end{array}$ \\
\hline $\begin{array}{l}\text { University of Illinois at Urbana- } \\
\text { Champaign [158] }\end{array}$ & $\begin{array}{l}\text { AOXADUR which consists of } \\
\text { three additives: aldehyde, } \\
\text { thioester, and a caltalyst. }\end{array}$ & $\begin{array}{l}\text { Stiffness, thermal stress and } \\
\text { cracking potential }\end{array}$ & $\begin{array}{l}\text { Dramatic increase in high- } \\
\text { temperature stiffness and } \\
\text { a substantial decrease in low- } \\
\text { temperature stiffness }\end{array}$ \\
\hline Dessouky and Diaz [170] & $\begin{array}{l}\text { Copolymers solution ethylene- } \\
\text { butylene/styrene (SEBS) and } \\
\text { solution styrene-butadiene } \\
\text { rubber (SSBR) with enhanced } \\
\text { antioxidant agents }\end{array}$ & Brittleness & $\begin{array}{l}\text { Copolymers improved the rutting } \\
\text { and moisture resistance of the } \\
\text { modified asphalt mixtures but } \\
\text { they decreased the fatigue life } \\
\text { compared to the control mixture }\end{array}$ \\
\hline
\end{tabular}

Combinations of various antioxidants were also evaluated by Apeagyei [59] to determine whether synergistic behavior existed between any of the antioxidants. These additives included DLTDP/furfural, hydrated lime, vitamin E, carbon black, Irgafos P-EPQ, and Irganox 1010. The DSR was used to examine the rheological properties of untreated and antioxidant-modified binders. The findings of this study illustrate that the combination of furfural and DLTDP additives had the lowest aging index compared to the other modifiers. This specific combination provided a 40 percent reduction in aging/hardening compared to unmodified binders. In general, the antioxidant-modified binders had a lower stiffness modulus and flexural stiffness compared to untreated binders, which is expected to have better cracking resistance. The author recommended further research to validate the results using additional binders and to evaluate the properties of both asphalt mixtures and binders.

Reyes [168] assessed the potential of using vitamin E as an antioxidant modifier with two types of binder: unmodified (PG 64-22) and modified (PG 70-22). As vitamin E has low viscosity, two calcium-based additives (Hydrated Lime and Fly-Ash) were used as stabilization agents to increase the stiffness of the binder. The researcher used high shear rate blender at $2100 \mathrm{rpm}$ for 1 hour for mixing each samples. The results of this study show that the use of vitamin $\mathrm{E}$ reduced the viscosity of the binders. Also, the use of stabilization agents such as fly ash and hydrated lime improved the stiffness of the antioxidant vitamin E-modified binders. The modified binders with vitamin $\mathrm{E}$ had desirable characteristics that would resist fatigue cracking; however, there was a concern about rutting resistance. The antioxidant vitamin E-modified binder had reduced stiffness modulus and increased phase angle. The author suggested that experiments be conducted to determine optimum antioxidant and stabilization agent percentages to achieve better performance with aging.

Pan et al. [52] performed an atomistic-based chemophysical analysis to facilitate the fundamental understanding of the aging and antioxidation mechanisms and thereby to develop antiaging strategies. In this study, the chemical and physical bases of asphalt oxidation as well as the antioxidation mechanism of coniferyl-alcohol lignin was investigated. The researchers developed a quantum chemistrybased chemophysical environment and studied various chemical reactions between asphalt components and oxygen and the resulting physical changes on the contrary to the 


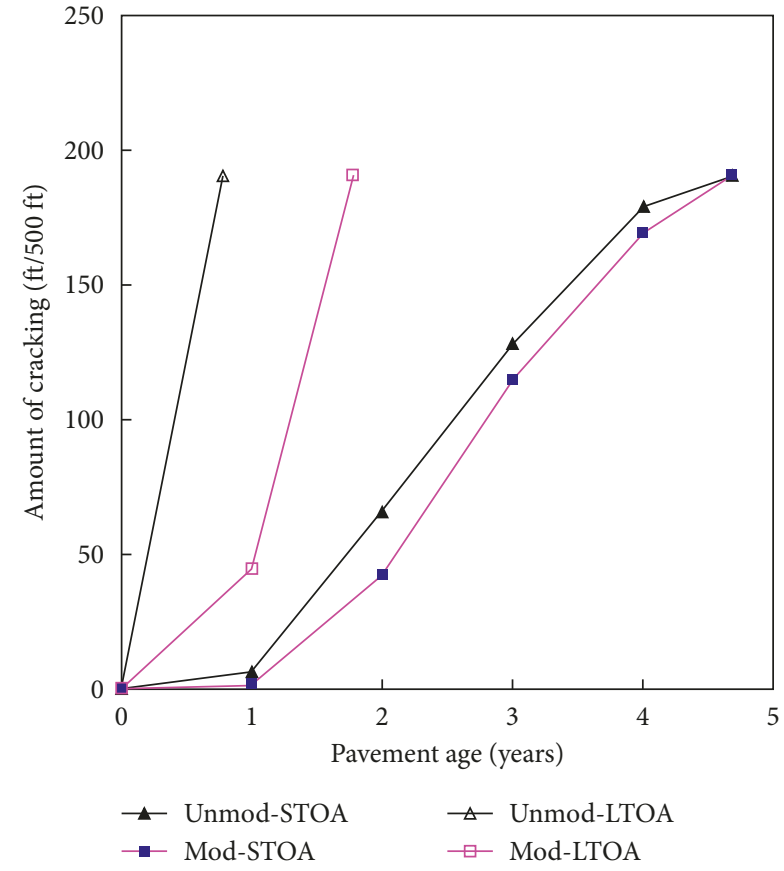

FIGURE 7: Effect of aging on thermal cracking of AOX-modified and unmodified asphalt mixtures (from Apeagyei [167]).

traditional evaluation method of the degradation of asphalt physical properties (i.e., viscosity and ductility). Two distinct stages of asphalt aging were identified; asphalts initially exhibit a high chain-breaking trend and a high reactivity with oxygen, causing a rapid spurt in the formation of lightmolecular-weight alkanes, ketones, and sulfoxides, and the spurt is followed by a slower rate of oxidation and hardening. The authors suggested that coniferyl-alcohol lignin can be used as antioxidant for petroleum asphalt, with the maximum radical-scavenging effectiveness achieved in a nonoxidative condition of the lignin (e.g., $<130^{\circ} \mathrm{C}$ under 1 ATM oxygen partial pressure).

Williams [169] evaluated the potential of agriculturally derived lignin-containing ethanol coproducts for use as antioxidant in asphalt binder. The researcher used four coproducts mixed with four different types of asphalt binders in the range of $3-12 \%$ resulting in 52 treatment combinations. Three coproducts contained lignin processed from corn where the fourth one had its lignin removed and acted as a control to measure the antioxidant activity of the three other lignin coproducts. The performance testing of each combination consisted of DSR and bending beam Rheometer (BBR) testing coinciding with field simulative aging using a RTFOT and PAV. The results showed that the lignin-containing coproducts had beneficial antioxidant activity and stiffened the binder at all stages of aging. The researcher suggested that more separation testing should be conducted to evaluate the effect of variables such as physical size and chemical composition of the coproducts.

Depending on climatic condition, two distinct types of phenomena due to aging is observed in asphalt pavement. At low temperature, stiffness of asphalt is increased, and as a result, flexibility of the asphaltic concrete reduces, causing cracking in pavement due to fatigue or thermal stresses. Higher temperature, on the other hand, softens the asphalt and consequently reduces the stiffness of asphaltic concrete making the mix more susceptible to rutting. Some antioxidant treatments are promising in reducing binder stiffness but still prone to softening at higher temperature, stiffening at lower temperatures or leaching out over time.

In 2006, a team of researchers at the University of Illinois at Urbana-Champaign produced an antioxidant treatment using AOXADUR which consists of three additives: aldehyde, thioester, and a caltalyst. A condensation reaction of aldehyde with asphalt to form novolacs, which can act as antioxidants, results in a reduction of age-susceptible polar aromatics in the binder. The thioester serves as a secondary antioxidant, which is highly effective against oxidative degradation of hydrocarbons. Laboratory testing of over 40 binders at the University of Illinois showed that the AOXADUR-modified binder produces the lowest aging index and a dramatic increase in high-temperature stiffness and a substantial decrease in low-temperature stiffness. The researchers reported improvement in binder properties at both high and low temperatures results in less thermal stress and reduced cracking potential.

\section{Conclusions}

The following are the main points discussed in this paper.

(i) Asphalt aging is a complex phenomenon and affects performance of asphalt pavement by causing functional damage to asphalt. It is generally defined as change in the rheological properties of asphalt binders/mixtures due to changes in chemical composition during the construction and its service life period. Aging is influenced by intrinsic and extrinsic variables: intrinsic variables include asphalt binder mixture types, aggregate, void content, and film thickness and extrinsic variables are mixing temperature and environmental conditions. Aging affects asphalt pavement in many ways and makes it embrittle, of reduced damage tolerance and less durable. As a result, pavement becomes susceptible to disintegration and cracking failures at low temperatures.

(ii) Complex molecular structure of asphalt and its chemical components are changed as a result of exposure to temperature variation and atmospheric conditions resulting in alteration in asphalt properties. The main mechanisms for asphalt aging are identified as oxidation, volatilization, and steric hardening. During construction, asphalt binder is subjected to higher temperature which causes aging due to oxidation and loss of volatile compounds. On the contrary, long-term aging during service periods takes place at lower temperature primarily due to oxidation mechanism. Steric hardening occurs during long-term aging at relatively lower temperature. 
(iii) Extended heating by thin film oven and oxidation by air blowing are main methods to simulate aging of asphalt binder in laboratory environment. The most commonly used tests for simulating asphalt binder aging are the RTFOT and PAV tests. In this process, an asphalt binder to be evaluated is to be subjected RTFOT for short-term aging at $163^{\circ} \mathrm{C}$ for 85 minutes followed by a PAV process at $85^{\circ} \mathrm{C}$ for 5 days in order to simulate several years of field aging.

(iv) The standard protocol to simulate aging of asphalt mixture is to cure asphalt mixtures for 4 hours at $135^{\circ} \mathrm{C}$ for short-term aging and 5 days at $85^{\circ} \mathrm{C}$ for long-term aging. However, these standard aging protocols have limitations and cannot be applied for different environmental conditions. Therefore, development and validation of a new aging simulation procedure that accounts for different environmental conditions and mix properties such as air void content is highly desirable.

(v) Various antioxidant additives have been used to retard aging of asphalt pavement and thereby improving performance of flexible pavement and substantial savings in life cycle cost. One of the most desirable properties of asphalt mixture is to perform well at higher temperature against rutting as well as at lower temperature against cracking due to fatigue. Results from experimental research indicated that several additives performed well at higher temperature while showing poor performance at lower temperature or vice versa. Further research on a variety of antioxidant additives is warranted in order to obtain a more effective and sustainable asphalt mixture that can perform equally well both at high and low temperatures.

\section{Conflicts of Interest}

The authors declare that they have no conflicts of interest.

\section{Acknowledgments}

This paper was made possible by the NPRP grant (NPRP 6773-2-320) from the Qatar National Research Fund (a member of Qatar Foundation). The statements made herein are solely the responsibility of the authors.

\section{References}

[1] D. Lesueur, "The colloidal structure of bitumen: consequences on the rheology and on the mechanisms of bitumen modification," Advances in Colloid and Interface Science, vol. 145, no. 1-2, pp. 42-82, 2009.

[2] H. Abraham, Asphalt and Allied Substances, Van Nostrand, New York, NY, USA, 6th edition, 1960.

[3] D. Croney, The Design and Performance of Road Pavements, Her Majesty's Stationery Office, London, UK, 1977.

[4] L. C. Krchma and D. W. Gagle, "A USA history of asphalt refined from crude oil and its distribution," Proceedings of the Association of Asphalt Paving Technologists, 50th Anniversary Historical Review, vol. 43, pp. 26-88, 1974.
[5] A. W. Dow, "Asphalt Experiments at Washington," Engineering Record, vol. 47, no. 18, 1903.

[6] C. A. Bell, "Summary report on aging of asphalt-aggregate systems," Research Report No. SR-OCU-A-003A-89-2, SHRP-A-305, Strategic Highway Research Program, National Research Council, Washington, DC, USA, 1989.

[7] F. L. Roberts, P. S. Kandhal, E. R. Brown, D. Y. Lee, and T. W. Kennedy, Hot Mix Asphalt Materials, Mixture Design, and Construction, National Asphalt Pavement Association, Research and Education Foundation, Lanham, MD, USA, 1996.

[8] C. J. Glover, E. Martin, A. Chowdhury et al., "Evaluation of binder aging and its influence in aging of hot mix asphalt concrete: literature review and experimental design," Research Report No. FHWA/TX-08/0-6009-1, Texas Transportation Institute, College Station, TX, USA, 2009.

[9] N. Morian, E. Y. Hajj, and P. E. Sebaaly, "Significance of mixture on binder aging in HMA mixtures," in Proceedings of 92nd Annual Meeting of Transportation Research Record, Washington, DC, USA, January 2013.

[10] R. N. Traxler, "Relation between asphalt composition and hardening by volatilization and oxidation," Proceedings of Association of Asphalt Paving Technologists, vol. 30, pp. 359-377, 1961.

[11] J. W. Lund and J. E. Wilson, "Evaluation of asphalt aging in hot mix plants," Journal of the Association of Asphalt Paving Technologists, vol. 53, pp. 1-18, 1984.

[12] J. W. Lund and J. E. Wilson, "Field validation of asphalt aging in hot mix plants," Journal of the Association of Asphalt Paving Technologists, vol. 55, pp. 92-119, 1984.

[13] A. Topal and B. Sengoz, "Effect of SBS polymer modified bitumen on the ageing properties of asphalt," in Proceedings of the 4th Eurasphalt and Eurobitume Congress, European Asphalt Pavement Association, Copenhagen, Denmark, 2008.

[14] D. Zhao, M. Lei, and Z. Yao, "Evaluation of polymermodified hot-mix asphalt: laboratory characterization," Journal of Materials in Civil Engineering, vol. 21, no. 4, pp. 163-170, 2009.

[15] N. Morian, E. Y. Hajj, C. J. Glover, and P. E. Sebaaly, "Oxidative aging of asphalt binders in hot mix asphalt mixtures," in Transportation Research Record: Journal of the Transportation Research Board, No. 2207, pp. 107-116, Transportation Research Board of the National Academies, Washington, DC, USA, 2011.

[16] P. S. Kandhal and S. Chakraborty, "Effect of asphalt film thickness on short-and long-term aging of asphalt paving mixtures," Transportation Research Record: Journal of the Transportation Research Board, vol. 1535, no. 1, pp. 83-90, 1996.

[17] E. H. Chipperfield and T. R. Welch, "Studies on the relationships between the properties of road bitumens and their service performance," Journal of the Association of Asphalt Paving Technologists, vol. 36, pp. 421-488, 1967.

[18] T. Aschenbrener and N. Far, "Short-term aging of hot mix asphalt," Report No. CDOT-DTD-R-94-11, Colorado Department of Transportation Public, Denver, CO, USA, 1994.

[19] W. Mogawer, T. Bennert, J. S. Daniel, R. Bonaquist, A. Austerman, and A. Booshehrian, "Performance characteristics of plant produced high RAP mixtures," Journal of the Association of Asphalt Paving Technologists, vol. 80, pp. 403-439, 2012.

[20] R. L. Terrel and D. J. Holen, "Performance of asphalt concrete pavement mixtures produced by the drum mixer 
process," Journal of the Association of Asphalt Paving Technologists, vol. 45, pp. 169-198, 1976.

[21] B. H. Chollar, J. A. Zenewitz, J. G. Boone, K. T. Tran, and D. T. Anderson, Changes Occurring in Asphalts in Drum Dryer and Batch (Pug Mill) Mixing Operations, pp. 145-155, Transportation Research Record 1228, TRB, National Research Council, Washington, DC, USA, 1989.

[22] J. S. Daniel, T. Bennert, Y. R. Kim, and W. Mogawer, "TPF 5(230): evaluation of plant-produced RAP mixtures in the Northeast," Pooled Fund Phase I Interim Report, Federal Highway Administration, Washington, DC, USA, 2014.

[23] G. R. Kemp and N. H. Prodoehl, "A comparison of field and laboratory environments on asphalt durability," Proceedings of Association of Asphalt Paving Technologists, vol. 50, pp. 492-537, 1981.

[24] W. J. Kari, "Effect of construction practices on the asphalt properties in the mix," in Proceedings of the Annual Conference of Canadian Technical Asphalt Association, vol. 27, pp. 310-334, Halifax, NS, Canada, November 1982.

[25] J. Rolt, “Top-down cracking: myth or reality?," in Proceedings of the World Bank Regional Seminar on Innovative Road Rehabilitation and Recycling Technologies, Amman, Jordan, 2000.

[26] E. T. Harrigan, NCHRP Research Results Digest 324: Simulating the Effects of Hot Mix Asphalt Aging for Performance Testing and Pavement Structural Design, Transportation Research Board, Washington, DC, USA, 2007.

[27] W. N. Houston, M. W. Mirza, C. E. Zapata, and S. Raghavendra, "Environmental effects in pavement mix and structural design systems," Part 1 of Contractor's Final Report for NCHRP Project 9-23, Arizona State University, Phoenix, AZ, USA, 2005.

[28] M. J. Farrar, T. F. Turner, J. Planche, J. F. Schabron, and P. M. Harnsberger, "Evolution of the crossover modulus with oxidative aging: method to estimate change in viscoelastic properties of asphalt binder with time and depth on the road," in Transportation Research Record: Journal of the Transportation Research Board, No. 2370, pp. 76-83, Transportation Research Board, Washington, DC, USA, 2013.

[29] O. Sirin, M. Ohiduzzaman, E. Kassem, and D. K. Paul, (Under review). Comprehensive Evaluation of Long-Term Aging of Asphalt Mixtures in Hot Climatic Condition Submitted for Publication to Journal of Road Materials and Pavement Design (Manuscript ID RMPD-17-09-17).

[30] S. Wu, Z. Zhao, Y. Xiao, M. Yi, Z. Chen, and M. Li, "Evaluation of mechanical properties and aging index of 10year field aged asphalt materials," Construction and Building Materials, vol. 155, pp. 1158-1167, 2017.

[31] A. Epps Martin, E. Arambula, F. Yin et al., "Evaluation of the moisture susceptibility of WMA technologies," NCHRP Report 763, Transportation Research Board, Washington, DC, USA, 2014

[32] D. Y. Lee, "Asphalt durability correlation in Iowa," Transportation Research Record, vol. 468, pp. 43-60, 1973.

[33] M. N. Siddiqui and M. F. Ali, "Investigation of chemical transformations by NMR and GPC during the laboratory aging of Arabian asphalt," Fuel, vol. 78, no. 12, pp. 1407$1416,1999$.

[34] O. Sirin, D. K. Paul, M. Ohiduzzaman, and E. Kassem, "Effect of ageing on asphalt binders in the State of Qatar: a case study," Road Materials and Pavement Design, vol. 18, Issue sup 4, pp. 165-184, 2017.

[35] Y. Ab Wahab, D. Sosnovske, C. Bell, and P. Ryus, "Evaluation of asphalt-aggregate mixture aging by dynamic mechanical analysis," Transportation Research Record, vol. 1386, pp. 22-30, 1993.

[36] B. A. Vallerga, "Pavement deficiencies related to asphalt durability," Proceedings of Association of Asphalt Paving Technologists, vol. 50, pp. 481-491, 1981.

[37] C. A. Bell, J. E. Kliewer, and D. A. Sosnovke, "Investigation of the relationship between field performance and laboratory aging properties of asphalt mixtures," in Engineering Properties of Asphalt Mixtures and the Relationship with Their Performance, G. A. Huber and D. S. Decker, Eds., ASTM STP 1265, American Society for Testing and Materials, Philadelphia, PA, USA, 1995.

[38] E. Rahmani, E. M. Darabi, D. N. Little, and E. A. Masad, "Constitutive modeling of coupled aging-viscoelastic response of asphalt concrete," Construction and Building Materials, vol. 131, pp. 1-15, 2017.

[39] E. J. Barth, Asphalt, Gordon \& Breach, New York, NY, USA, 1962.

[40] D. K. Paul, O. Sirin, and E. Kassem, "Laboratory investigation of asphalt mixture aging," in Proceedings of 6 th Eurasphalt \& Eurobitume Congress, At Prague, Czech Republic, 2016.

[41] J. F. Branthaver, J. C. Petersen, R. E. Robertson et al., "Binder characterization and evaluation: chemistry," Report No SHRP-A-368, vol. 2, SHRP, National Research Council, Washington, DC, USA, 1993

[42] M. Mortazavi and J. S. Moulthrop, "SHRP materials reference library," SHRP Report A-646, National Research Council, Washington, DC, USA, 1993.

[43] J. G. Speight, The Chemistry and Technology of Petroleum, Marcel Dekker, New York, NY, USA, 3rd edition, 1999.

[44] J. Read and D. Whiteoak, The Shell Bitumen Handbook, Thomas Telford Publishing, London, UK, 5th edition, 2003.

[45] Asphalt Institute, Performance Graded Asphalt Binder Specification and Testing, Superpave Series no. 1, SP-1, Asphalt Institute, San Jose, CA, USA, 3rd edition, 2003.

[46] L. W. Corbett, "Composition of asphalt based on generic fractionation using solvent deasphalteneing, elutionadsorption chromatography and densiometric characterization," Analytical Chemistry, vol. 41, no. 4, pp. 576-579, 1969.

[47] F. S. Rostler and R. M. White, "Composition and changes in composition of highway asphalt, 85-100 Penetration Grade," Proceedings of Association of Asphalt Paving Technologists, vol. 31, pp. 35-89, 1962.

[48] Asphalt Institute, Paving Asphalt. Educational Series, No. 8 (ES-8), Asphalt Institute, San Jose, CA, USA, 1980.

[49] F. N. Hveem, E. Zube, and J. Skog, "Progress report on the zacawigmore experimental asphalt test project," ASTM Special Technical Publication, vol. 277, pp. 1-45, 1959.

[50] H. Plancher, E. L. Green, and J. C. Petersen, "Reduction of oxidative hardening of asphalts by treatment with hydrated lime-a mechanistic study," Proceedings of Association of Asphalt Paving Technologists, vol. 45, pp. 1-24, 1976.

[51] J. C. Petersen, "Chemical composition of asphalt as related to asphalt durability: state of the art," Transportation Research Record, vol. 999, pp. 13-30, 1984.

[52] T. Pan, L. Sun, and Q. Yu, "An atomistic-based chemophysical environment for evaluating asphalt oxidation and antioxidants," Journal of Molecular Modeling, vol. 18, no. 12, pp. 5113-5126, 2012.

[53] K. W. Kim and J. L. Burati Jr., "Use of GPC chromatograms to characterize aged asphalt cements," Journal of Materials in Civil Engineering, vol. 5, no. 1, pp. 41-52, 1993. 
[54] J. N. Shen, S. N. Amirkhanian, and F. P. Xiao, HP-GPC Characterization of Aging of Recycled CRM Binders Containing Rejuvenating Agents, Transportation Research Board, Washington, DC, USA, 2005.

[55] U. Heneash, Effect of the Repeated Recycling on Hot Mix Asphalt Properties, Ph.D. thesis, University of Nottingham, Nottingham, UK, 2013.

[56] J. Y. Welborn, Relationship of Asphalt Cement Properties to Pavement Durability, National Cooperative Highway Research Program, Synthesis 59, Transportation Research Board, Washington, DC, USA, 1979.

[57] C. A. Bell, A. J. Wieder, and M. J. Fellin, "Laboratory aging of asphalt-aggregate mixtures: field validation," Research Report SHRP-A-390, Oregon State University, Corvallis, OR, USA, 1994.

[58] G. Airey, "State of the art report on ageing test methods for bituminous pavement materials," International Journal of Pavement Engineering, vol. 4, no. 3, pp. 165-176, 2003.

[59] A. K. Apeagyei, "Laboratory evaluation of antioxidants for asphalt binders," Construction and Building Materials, vol. 25 , no. 1 , pp. 47-53, 2011.

[60] D. A. Anderson and R. Bonaquist, "Investigation of shortterm laboratory aging of neat and modified asphalt binders," Research Report NCHRP-709, Transportation Research Board, Washington, DC, USA, 2012.

[61] D. Y. Lee and R. J. Huang, "Weathering of asphalts as characterized by infrared multiple internal reflection spectra," Applied Spectroscopy, vol. 27, no. 6, pp. 435-440, 1973.

[62] C. K. Lau, K. M. Lunsford, C. J. Glover, R. R. Davison, and J. A. Bullin, "Reaction rates and hardening susceptibilities as determined from pressure oxygen vessel aging of asphalts," Transportation Research Record, vol. 1342, pp. 50-57, 1992.

[63] J. C. Petersen, J. F. Branthaver, R. E. Robertson, P. M. Harnsberger, J. J. Duvall, and E. K. Ensley, "Effects of physicochemical factors on asphalt oxidation kinetics," Transportation Research Record, vol. 1391, pp. 1-10, 1993.

[64] T. C. Davis and J. C. Petersen, "An inverse GLC study of asphalts used in the Zaca-Wigmore experimental test road," Proceedings of Association of Asphalt Paving Technologists, vol. 36, pp. 1-15, 1967.

[65] J. C. Petersen, “Asphalt aging: a dual oxidation mechanism and its inter-relationships with asphalt composition and oxidative age hardening," Transportation Research Record, vol. 1638, pp. 47-55, 1998.

[66] R. F. Coons and P. H. Wright, "An investigation of the hardening of asphalt recovered from pavements of various ages," Association of Asphalt Paving Technologists, vol. 37, p. $510,1968$.

[67] AASHTO, Guide for Mechanistic-Empirical Design of New and Rehabilitated Pavement Structures, NCHRP 1-37A, AASHTO, Washington, DC, USA2004, http://trb. org/mepdg.

[68] L. F. Walubita, A. E. Martin, S. H. Jung et al., "Comparison of fatigue analysis approaches for two hot mix asphalt concrete (HMA) mixtures," Report FHWA/TX-05/0-4468-2, Texas Transportation Institute, College Station, TX, USA, 2005.

[69] L. F. Walubita, Comparison of Fatigue Analysis Approaches for Predicting Fatigue Lives of Hot Mix Asphalt Concrete Mixtures (HMA), Ph.D. Dissertation, Texas A\&M University, College Station, TX, USA, 2006.

[70] C. J. Glover, R. R. Davison, C. H. Domke et al., "Development of new method for assessing asphalt binder durability with field validation," Report FHWA/TX-05/1872-2, Texas Transportation Institute, College Station, TX, USA, 2005.
[71] N. A. Al-Azri, S. H. Jung, K. M. Lunsford et al., "Binder oxidative aging in texas pavements," Transportation Research Record: Journal of the Transportation Research Board, vol. 1962, pp. 12-20, 2006.

[72] R. Abu Al-Rub, M. Darabi, S. Kim, D. Little, and C. Glover, "Mechanistic-based constitutive modeling of oxidative ageing in ageing susceptible materials and its effect on the damage potential of asphalt concrete," Construction and Building Materials, vol. 41, pp. 439-454, 2013.

[73] J. R. Wright, "Weathering: theoretical and practical aspects of asphalt durability," in Bituminous Materials: Asphalts, Tars and Pitches, A. J. Hoiberg, Ed., vol. 2, no. 1, pp. 249-306, Interscience Publishers, New York, NY, USA, 1965.

[74] L. W. Corbett and R. E. Merz, "Asphalt binder hardening in the Michigan test road after 18 years of service," Transportation Research Record, vol. 544, pp. 27-34, 1975.

[75] M. Liu, M. A. Ferry, R. R. Davison, C. J. Glover, and J. A. Bullin, "Oxygen uptake as correlated to carbonyl growth in aged asphalts and asphalt corbett fractions," Journal of the Industrial and Engineering Chemistry Research, vol. 37, no. 12 , pp. $4669-4674,1998$.

[76] F. Farcas, "Etude d'une methode de simulation du vieillissement sur route des bitumes," Ph.D. thesis, Pierre and Marie Cury University, Paris, France, 1996, in French.

[77] M. Zupanick and V. Baselice, "Characterizing asphalt volatility," Transportation Research Record, vol. 1586, pp. 1-9, 1997.

[78] A. Shalaby, "Modelling short-term aging of asphalt binders using the rolling thin film oven test," Canadian Journal of Civil Engineering, vol. 29, pp. 135-144, 2002.

[79] W. D. Fernández-Gómez, H. Rondón Quintana, and F. Reyes Lizcano, "A review of asphalt and asphalt mixture aging," Ingeniería e Investigación, vol. 33, no. 1, pp. 5-12, 2013.

[80] D. W. Christensen and D. A. Anderson, "Interpretation of dynamic mechanical test data for paving grade asphalt cements," Journal of the Association of Asphalt Paving Technologists, vol. 61, pp. 67-116, 1992.

[81] P. C. Cui, S. Wu, Y. Xiao, and H. Zhang, "Study on the deteriorations of bituminous binder resulted from volatile," Construction and Building Materials, vol. 68, pp. 644-649, 2014.

[82] J. F. Masson, P. Collins, and G. Polomark, "Steric hardening and the ordering of asphaltenes in bitumen," Energy and Fuels, vol. 19, no. 1, pp. 120-122, 2005.

[83] B. G. Pechenyi and O. I. Kuznetsov, "Formation of equilibrium structures in bitumens," Chemistry and Technology of Fuels and Oils, vol. 26, no. 7, pp. 372-376, 1990.

[84] D. Swiertz, Asphalt Aging Characteristics, Rheological Implications and Laboratory Techniques, University of Wisconsin, Madison, WI, USA, 2010.

[85] V. Nicholson, "A laboratory oxidation test for asphaltic bitumens," Proceedings of Association of Asphalt Paving Technologists, vol. 9, pp. 208-214, 1937.

[86] C. L. Shattuck, "Measurement of the resistance of oil asphalts (50-60 Pen) to changes in penetration and ductility at plant mixing temperatures," Proceedings of Association of Asphalt Paving Technologists, vol. 11, pp. 186-203, 1940.

[87] D. Y. Lee, "Development of a laboratory durability test for asphalts," Highway Research Board, vol. 231, pp. 34-49, 1968.

[88] L. E. Santucci, J. E. Goodrich, and J. E. Sundberg, "The effect of crude source and additives on long-term oven ageing of paving asphalts," Proceedings of Association of Asphalt Paving Technologists, vol. 50, pp. 560-571, 1981. 
[89] R. L. McHattie, Estimating the Durability of Chem-Crete Modified Paving Asphalt, Alaska Department of Transportation, Juneau, AK, USA, 1983.

[90] H. Von Quintus, J. Scherocman, T. Kennedy, and C. S. Hughes, "Asphalt aggregate mixture analysis system," Final Report to NCHRP 09-06(1), National Research Council, Washington, DC, USA, 1988.

[91] M. Tia, B. E. Ruth, C. T. Charai, J. M. Shiau, D. Richardson, and J. Williams, "Investigation of original and in-service asphalt properties for the development of improved specifications- final phase of testing and analysis," Final Report," Engineering and Industrial Experiment Station, University of Florida, Gainesville, FL, USA, 1988.

[92] J. C. Petersen, "A thin-film accelerated aging test for evaluating asphalt oxidative aging," Proceedings of Association of Asphalt Paving Technologists, vol. 58, pp. 220-237, 1989.

[93] H. U. Bahia and D. A. Anderson, "The pressure aging vessel (PAV): a test to simulate rheological changes due to field aging," in Proceeding of Physical Properties of Asphalt Cement Binders, pp. 67-88, Dallas, Texas, USA, 1995.

[94] T. V. Scholz, Durability of Bituminous Paving Mixtures, Ph. D. thesis, School of Civil Engineering, University of Nottingham, Nottingham, UK, 1995.

[95] M. W. Mirza and M. W. Witczak, "Development of a global aging system for short and long term aging of asphalt cements," Journal of the Association of Asphalt Paving Technologists, vol. 64, pp. 393-430, 1995.

[96] H. U. Bahia, W. P. Hislop, H. Zhai, and A. Rangel, "Classification of asphalt binders into simple and complex binders," Journal of the Association of Asphalt Paving Technologists, vol. 67, pp. 1-41, 1998.

[97] H. A. Khalid and C. M. Walsh, "Relating mix and binder fundamental properties of aged porous asphalt materials," in Proceedings of 2nd Eurasphalt \& Eurobitume Congress, Session 1: Performance Testing and Specifications for Binder and Mixtures, pp. 398-405, Barcelona, Spain, 2000.

[98] R. B. Mallick and E. R. Brown, "An evaluation of superpave binder aging methods," International Journal of Pavement Engineering, vol. 5, no. 1, pp. 9-18, 2004.

[99] X. Luo, A. Epps Martin, R. Luo, R. L. Lytton, and C. J. Glover, "Aging experiment design including revised cmse testing protocols and analysis to characterize mixture fatigue resistance," Research Report No. FHWA-DTFH61-07H-0009, Texas Transportation Institute, College Station, TX, USA, 2008.

[100] ASTM, Standard Test Method for Effect of Heat and Air on a Moving Film of Asphalt (Rolling Thin-Film Oven Test), D2872-2012, Annual Book of ASTM Standards, ASTM International, West Conshohocken, PA, USA, 2012.

[101] AASHTO, Standard Method of Test for Effect of Heat and Air on a Moving Film of Asphalt Binder (Rolling Thin-Film Oven Test), T240 AASHTO Provisional Standards, American Association of State Highway and Transportation Officials, Washington, DC, USA, 2013.

[102] ASTM, Standard Test Method for Effect of Heat and Air on Asphaltic Materials (Thin-Film Oven Test), D1754-09, Annual Book of ASTM Standards, ASTM International, West Conshohocken, PA, USA, 2009.

[103] AASHTO, Standard Method of Test for Effect of Heat and Air on Asphalt Materials (Thin-Film Oven Test), T179 AASHTO Provisional Standards, American Association of State Highway and Transportation Officials, Washington, DC, USA, 2009.

[104] AASHTO, Accelerated Aging of Asphalt binder using a Pressurized Aging Vessel (PAV) Standard Specifications,
R28-09 Provisional Standards, American Association of State Highway and Transportation Officials, Washington, DC, USA, 2009.

[105] R. H. Lewis and J. Y. Welborn, "Report on the properties of the residues of 50-60 and 85-100 penetration asphalts from oven tests and exposure," Proceedings of Association of Asphalt Paving Technologists, vol. 11, pp. 86-157, 1940.

[106] A. C. Edler, M. M. Hattingh, V. P. Servas, and C. P. Marais, "Use of ageing tests to determine the efficacy of hydrated lime additions to asphalt in retarding its oxidative hardening," Proceedings of Association of Asphalt Paving Technologists, vol. 54, pp. 118-139, 1985.

[107] R. L. Griffin, T. K. Miles, and C. J. Penther, "Microfilm durability test for asphalt," Proceedings of Association of Asphalt Paving Technologists, vol. 24, pp. 31-62, 1955.

[108] R. J. Schmidt and L. E. Santucci, "The effects of asphalt properties on the fatigue cracking of asphalt concrete on the Zaca-Wigmore test project," Proceedings of Association of Asphalt Paving Technologists, vol. 38, pp. 39-64, 1969.

[109] F. N. Hveem, E. Zube, and J. Skog, "Proposed new tests and specifications for paving grade asphalts," Proceedings of Association of Asphalt Paving Technologists, vol. 32, pp. 247-327, 1963.

[110] C. D. Whiteoak, Shell Bitumen Handbook, Thomas Telford, Surrey, UK, 1990.

[111] O. Sirin, C.-T. Shih, M. Tia, and B. E. Ruth, "Development of a modified rotavapor apparatus and method for short-term aging of modified asphalts," Transportation Research Record, vol. 1638, pp. 72-81, 1998.

[112] N. Y. Vassilev, R. R. Davison, and C. J. Glover, "Development of a stirred airflow test procedure for short-term aging of asphaltic concrete," Transportation Research Record, vol. 1810, pp. 25-32, 2007.

[113] S.-J. Lee, S. N. Amirkhanian, K. Shatanawi, and K. W. Kim, "Short-term aging characterization of asphalt binders using gel permeation chromatography and selected Superpave binder tests," Construction and Building Materials, vol. 22, pp. 2220-2227, 2007.

[114] R. E. Robertson, J. F. Branthaver, P. M. Harnsberger et al., "Fundamental properties of asphalts and modified asphalts," Interpretive Report, FHWA-RD-99-212, vol. 1, U. S. Department of Transportation, Federal Highway Administration, McLean, VA, USA, 2001.

[115] C. J. Glover, R. R. Davison, and N. Vassilie, "Development of stirred air flow test (SAFT) for Improved HMAC plant binder aging simulation and studies of asphalt air blowing," Report Number FHWA/TX-02/1742-4, Texas Department of Transportation, 2001.

[116] A. F. Verhasselt and F. S. Choquet, "A new approach to studying the kinetics of bitumen ageing," in Proceedings of Chemistry of Bitumens: International Symposium, vol. 2, pp. 686-705, Rome, Italy, 1991.

[117] J. C. Petersen, R. E. Robertson, D. A. Anderson, D. W. Christensen, J. W. Button, and C. J. Glover, "Binder characterization and evaluation volume 4: test methods, SHRP-A-403," Strategic Highway Research Program (National Research Council), Washington, DC, USA, 1994.

[118] B. Hayton, R. C. Elliott, G. D. Airey, and C. S. Raynor, "Long term ageing of bituminous binders," in Proceedings of Eurobitume Workshop 99, Paper No. 126, Luxembourg, 1999.

[119] V. Bellitto, Atomic Force Microscopy-Imaging, Measuring and Manipulating Surfaces at the Atomic Scale, InTech, Rijeka, Croatia, 2012. 
[120] P. K. Das, H. Baaj, S. Tighe, and N. Kringos, "Atomic force microscopy to investigate asphalt binders: a state-of-the-art review," Road Materials and Pavement Design, vol. 17, no. 3, pp. 693-718, 2016.

[121] L. Loeber, O. Sutton, J. Morel, J. M. Valleton, and G. Muller, "New direct observations of asphalts and asphalt binders by scanning electron microscopy and atomic force microscopy," Journal of Microscopy, vol. 182, no. 1, pp. 32-39, 1996.

[122] A. Jäger, R. Lackner, C. Eisenmenger-Sittner, and R. Blab, "Identification of four material phases in bitumen by atomic force microscopy," Road Materials and Pavement Design, vol. 5, no. 1, pp. 9-24, 2004.

[123] H. L. Zhang, J. Y. Yu, Z. G. Feng, L. H. Xue, and S. P. Wu, "Effect of aging on the morphology of bitumen by atomic force microscopy: effect of aging on morphology of bitumen," Journal of Microscopy, vol. 246, no. 1, pp. 11-19, 2012.

[124] R. G. Allen, D. N. Little, A. Bhasin, and R. L. Lytton, "Identification of the composite relaxation modulus of asphalt binder using AFM nanoindentation," Journal of $\mathrm{Ma}$ terials in Civil Engineering, vol. 25, no. 4, pp. 530-539, 2013.

[125] L. M. Rebelo, J. S. de Sousa, A. S. Abreu et al., "Aging of asphaltic binders investigated with atomic force microscopy," Fuel, vol. 117, pp. 15-25, 2014.

[126] P. K. Das, N. Kringos, and B. Birgisson, "Microscale investigation of thin film surface ageing of bitumen: Microscale investigation of bitumen surface ageing," Journal of $\mathrm{Mi}$ croscopy, vol. 254, no. 2, pp. 95-107, 2014.

[127] S.-C. Huang and A. T. Pauli, "Particle size effect of crumb rubber on rheology and morphology of asphalt binders with long-term aging," Road Materials and Pavement Design, vol. 9, no. 1, pp. 73-95, 2008.

[128] S. Wu, L. Pang, L. Mo, Y. Chen, and G. Zhu, "Influence of aging on the evolution of structure, morphology and rheology of base and SBS modified bitumen," Construction and Building Materials, vol. 23, no. 2, pp. 1005-1010, 2009.

[129] P. E. Y. Wang, K. Zhao, C. Glover et al., "Effects of aging on the properties of asphalt at the nanoscale," Construction and Building Materials, vol. 80, no. 2015, pp. 244-254, 2015.

[130] Z.-G. Feng, J.-Y. Yu, H.-L. Zhang, D.-L. Kuang, and L.-H. Xue, "Effect of ultraviolet aging on rheology, chemistry and morphology of ultraviolet absorber modified bitumen," Materials and Structures, vol. 46, no. 7, pp. 1123-1132, 2013.

[131] N. Morian, E. Y. Hajj, C. J. Glover, and P. E. Sebaaly, "Oxidative aging of asphalt binders in hot mix asphalt mixtures," Transportation Research Record, vol. 2207, pp. 107-116, 2012.

[132] P. Hubbard and H. Gollomb, "The hardening of asphalt with relation to development of cracks in asphalt pavements," Proceedings of the Association of Asphalt Paving Technologists, vol. 9, pp. 165-194, 1937.

[133] J. J. Heithaus and R. W. Johnson, "A microviscometer study of road asphalt hardening in the field and laboratory," Proceedings of the Association of Asphalt Paving Technologists, vol. 27, pp. 17-34, 1958.

[134] H. L. Von Quintus, J. A. Scherocman, C. S. Hughes, and T. W. Kennedy, "Asphalt-aggregate mixture analysis system: AAMAS,” NCHRP Report 338: TRB, National Research Council, Washington, DC, USA, 1991.

[135] J. S. Daniel and Y. R. Kim, "Laboratory evaluation of fatigue damage growth and healing of asphalt concrete mixtures using the impact resonance method," ASCE Journal of Materials in Civil Engineering, vol. 13, no. 6, pp. 434-440, 2001.
[136] C. Baek, B. S. Underwood, and Y. R. Kim, "Effects of oxidative aging on asphalt mixture properties," Transportation Research Record: Journal of the Transportation Research Board, vol. 2296, pp. 77-85, 2012.

[137] F. Yin, A. E. Martin, E. Arámbula-Mercado, and D. Newcomb, "Characterization of non-uniform field aging in asphalt pavements," Construction and Building Materials, vol. 153, pp. 607-615, 2017.

[138] M. D. Elwardany, F. Y. Rad, C. Castorena, and Y. R. Kim, "Evaluation of asphalt mixture laboratory long-term ageing methods for performance testing and prediction," Road Materials and Pavement Design, vol. 18, no. 1, pp. 28-61, 2017.

[139] M. R. Islam, M. I. Hossain, and R. A. Tarefder, "A study of asphalt aging using indirect tensile strength test," Construction and Building Materials, vol. 95, pp. 218-223, 2015.

[140] F. Moreno-Navarro, M. Sol-Sánchez, G. García-Travé, and M. C. Rubio-Gámez, "Fatigue cracking in asphalt mixtures: the effects of ageing and temperature," Road Materials and Pavement Design, vol. 19, no. 3, pp. 561-570, 2017.

[141] Y. Ying Gao, D. Geng, X. Huang, and G. Li, "Degradation evaluation index of asphalt pavement based on mechanical performance of asphalt mixture," Construction and Building Materials, vol. 140, pp. 75-81, 2017.

[142] H. Azari and A. Mohseni, "Effect of short-term conditioning and long-term ageing on permanent deformation characteristics of asphalt mixtures," Road Materials and Pavement Design, vol. 14, no. 2, pp. 79-91, 2013.

[143] L. F. A. L. Babadopulos, J. L. Ferreira, and J. B. Soares, "An approach to couple aging to stiffness and permanent deformation modeling of asphalt mixtures," Materials and Structutrers, vol. 49, no. 12, pp. 4929-4945, 2016.

[144] AASHTO, Standard Practice for Mixture Conditioning of Hot Mix Asphalt (HMA), R30 AASHTO Provisional Standards, American Association of State Highway and Transportation Officials, Washington, DC, USA, 2002.

[145] D. Newcomb, A. E. Martin, F. Yin et al., "Short-term laboratory conditioning of asphalt mixtures," NCHRP Report 815, Project 09-52, Transportation Research Board, Washington, DC, USA, 2015.

[146] K. Mollenhauer and V. Mouillet, Re-road-End of Life Strategies of Asphalt Pavements, European Commission DG Research, Ixelles, Belgium, 2011.

[147] M. N. Partl, H. U. Bahia, F. Canestrari et al., Advances in Interlaboratory Testing and Evaluation of Bituminous Materials, RILEM-Springer, Berlin, Germany, 2013.

[148] J. Reed, Evaluation of the Effects of Aging on Asphalt Rubber Pavements, Ph.D. Dissertation, Arizona State University, Tempe, AZ, USA, 2010.

[149] W. Van den Bergh, The Effect of Aging on Fatigue and Healing Properties of Bituminous Mortars, Ph.D. thesis, Delft University of Technology, Delft University, Delft, Netherlands, 2011.

[150] D. Gatchalian, E. Masad, A. Chowdhury, and D. Little, "Characterization of aggregate resistance to degradation in stone matrix asphalt mixtures," Journal of Transportation Research Board, vol. 1962, pp. 55-63, 2006.

[151] F. Y. Rad, M. D. Elwardany, C. Castorena, and Y. R. Kim, "Investigation of proper long-term laboratory aging temperature for performance testing of asphalt concrete," Construction and Building Materials, vol. 147, pp. 616-629, 2017.

[152] C. D. la Roche, M. Van de Ven, W. Van den bergh et al., Development of a Laboratory Bituminous Ageing Protocol. 
Advanced Testing and Characterization of Bituminous Materials, Taylor and Francis Group, London, UK, 2009.

[153] S. F. Said, "Aging effect on mechanical characteristics of bituminous mixtures," Transportation Research Record, vol. 1901, pp. 1-9, 2005.

[154] S. F. Brown and T. V. Scholz, "Development of laboratory protocols for the aging of asphalt mixtures," in Proceedings of 2nd Eurasphalt and Eurobitume Congress, vol. 1, pp. 83-90, Barcelona, Spain, September 2000.

[155] F. Yin, E. Arámbula-Mercado, E. Epps Martin, D. David Newcomb, and N. Tran, "Long-term aging of asphalt mixtures," Road Materials and Pavement Design, vol. 18, no. 1, pp. 2-27, 2017.

[156] P. Romero and R. Roque, "Progress of SUPERPAVE: evaluation and implementation," in Evaluation of Long-Term Oven Aging of Asphalt Mixtures on SUPERPAVE Thermal Cracking Performance Predictions, ASTM STP 1322, R. N. Jester, Ed., ASTM, West Conshohocken, PA, USA, 1997.

[157] F. N. Hveem, "Quality tests for asphalt-progress report," Proceedings of the Association of Asphalt Paving Technologists, vol. 15, 1943.

[158] A. K. Apeagyei, Development of Antioxidant Treatments for Asphalt Binders and Mixtures, Ph.D. Dissertation, University of Illinois at Urbana-Champaign, Champaign, IL, USA, 2008.

[159] J. H. W. Oliver, "Results of road trials of two asphalt antioxidants," Transportation Research Record, vol. 1488, pp. 96-102, 1995.

[160] K. G. Martin, "Laboratory evaluation of antioxidants for bitumen," in Australian Road Research Board Proceedings, vol. 4, Melbourne, VIC, Australia, 1968.

[161] B. D. Beitchman, "Effects of antioxidants on asphalt durability," Journal of Research of the National Bureau of Standards-C. Engineering and Instrumentation, vol. 64, no. 1, pp. 13-17, 1960.

[162] R. M. Januszke, "Paving asphalt additives in durability determination," Industrial \& Engineering Chemistry Product Research and Development, vol. 10, no. 2, pp. 209-214, 1971.

[163] H. E. Haxo and R. M. White, "Reducing the hardening of paving asphalts through the use of lead antioxidants," Association of Asphalt Paving Technologists Proceedings, vol. 48, pp. 611-645, 1979.

[164] J. C. Petersen, H. Plancher, and M. P. Hamsberger, "Lime treatment of asphalt to reduce age hardening and improve flow properties," Proceeding of the Association of Asphalt Paving Technologists, vol. 56, pp. 632-635, 1987.

[165] A. A. Mohamed, A Study on the Physical and Mechanical Properties of Asphaltic Concrete Incorporating Crumb Rubber Produced through Dry Process, Ph.D. thesis, Universiti Sains Malaysia, Kubang Kerian, Malaysia, 2007.

[166] A. K. Apeagyei, W. G. Buttlar, and B. J. Dempsey, "Antioxidant treatment of asphalt binders," US Patent Number US 20080210126 A1, 2008, http://www.google.com/patents/US20080210126.

[167] A. K. Apeagyei, W. G. Buttlar, and B. J. Dempsey, "Investigation of cracking behavior of antioxidant-modified asphalt mixtures," Association of Asphalt Paving Technologists, vol. 77, pp. 517-548, 2008.

[168] C. M. Reyes, Influence of Anti-Oxidant Modifications in Asphalt Binder Phesio-Chemical Properties and Mixes Performance, M.S. thesis, Department of Civil Engineering, The University of Texas at San Antonio, San Antonio, TX, USA, 2012.
[169] R. C. Williams, Using Lignin as an Asphalt Antioxidant, Centre for Transport Research and Education, Iowa State University, Ames, IA, USA, 2008, http://www.ctre.iastate. edu.

[170] S. Dessouky and M. Diaz, "Improving asphalt mixtures performance by mitigating oxidation using anti-oxidants additives," in Proceedings of TMS Middle EastMediterranean Materials Congress on Energy and Infrastructure Systems, pp. 45-54, Doha, Qatar, 2015. 


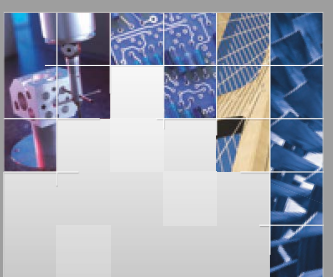

\section{Enfincering}
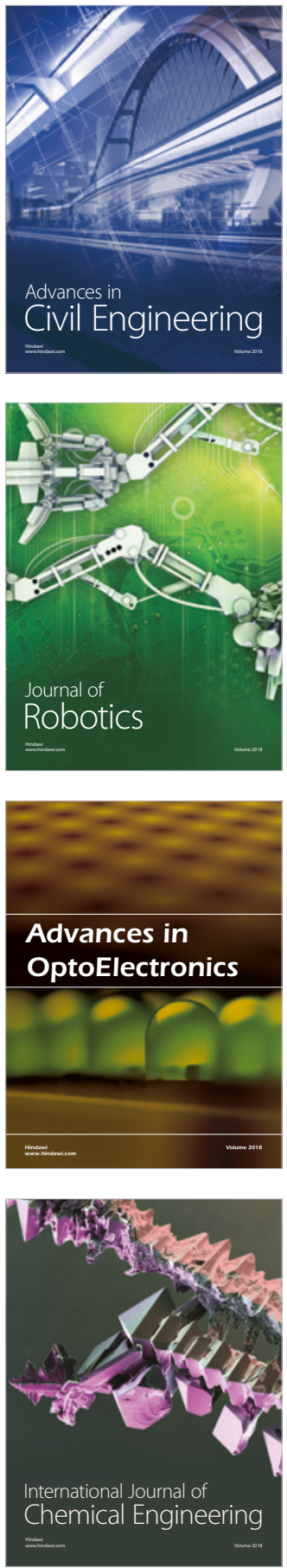

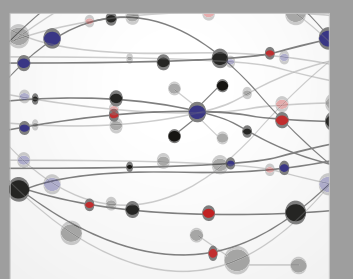

\section{Rotating \\ Machinery}

The Scientific World Journal

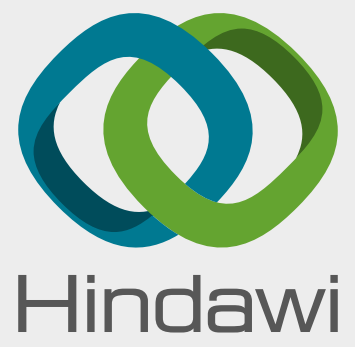

Submit your manuscripts at

www.hindawi.com
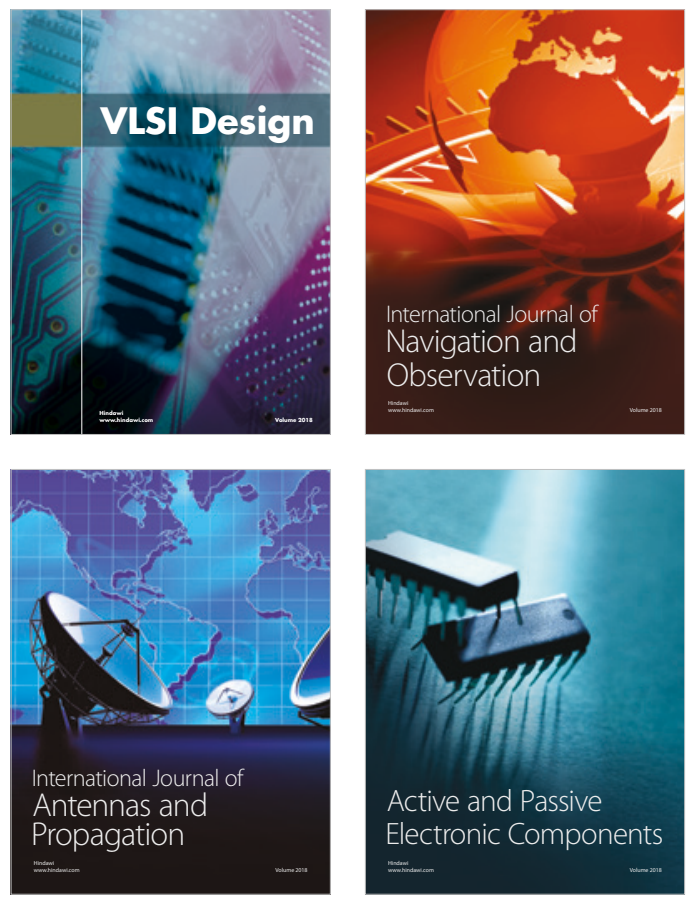
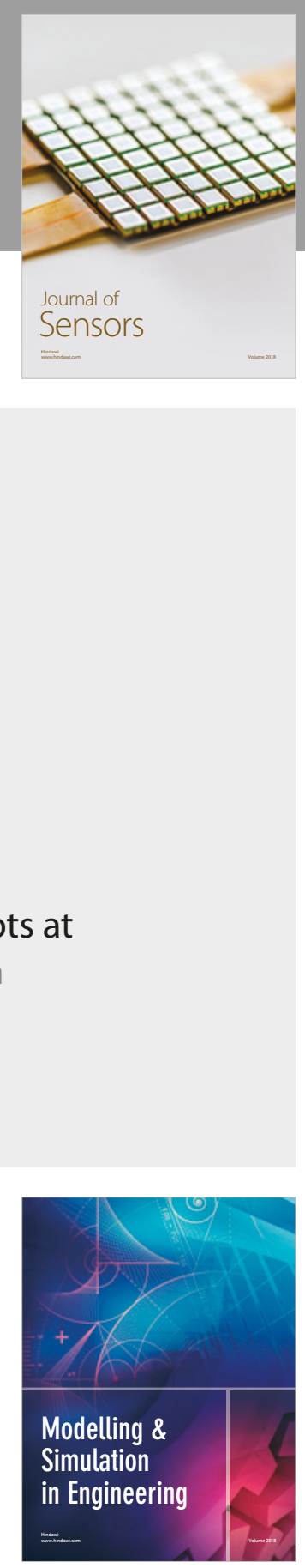

\section{Advances \\ Multimedia}
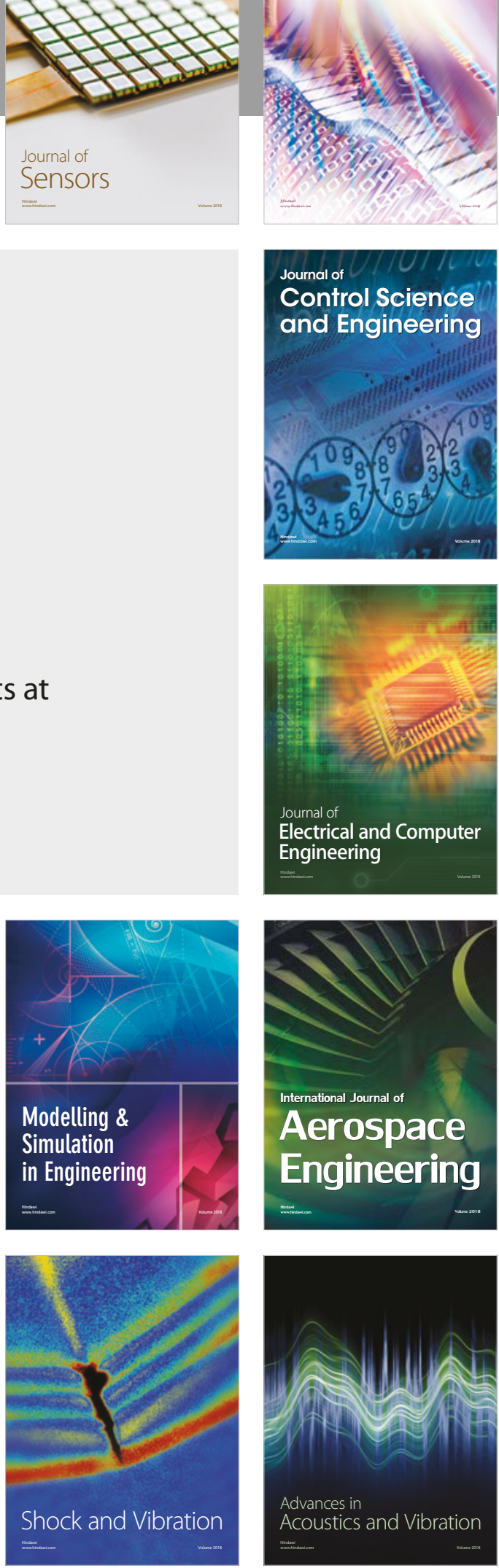